\title{
Metrics of hurricane-ocean interaction: vertically-integrated or vertically-averaged ocean temperature?
}

\author{
J. F. Price \\ Woods Hole Oceanographic Institution, Woods Hole, Massachusetts 02543, USA \\ Received: 1 April 2009 - Published in Ocean Sci. Discuss.: 5 May 2009 \\ Revised: 18 August 2009 - Accepted: 27 August 2009 - Published: 18 September 2009
}

\begin{abstract}
The ocean thermal field is often represented in hurricane-ocean interaction by a metric termed upper Ocean Heat Content $(\mathrm{OHC})$, the vertical integral of ocean temperature in excess of $26^{\circ} \mathrm{C}$. High values of $\mathrm{OHC}$ have proven useful for identifying ocean regions that are especially favorable for hurricane intensification. Nevertheless, it is argued here that a more direct and robust metric of the ocean thermal field may be afforded by a vertical average of temperature. In the simplest version, dubbed $T_{\overline{100}}$, the averaging is from the surface to $100 \mathrm{~m}$, a typical depth of vertical mixing by a category 3 hurricane. OHC and $T_{100}$ are well correlated over the deep open ocean in the high range of $\mathrm{OHC}, \geq 75 \mathrm{~kJ} \mathrm{~cm}^{-2}$. They are poorly correlated in the low range of $\mathrm{OHC}, \leq 50 \mathrm{~kJ} \mathrm{~cm}^{-2}$, in part because $\mathrm{OHC}$ is degenerate when evaluated on cool ocean regions, $\leq 26^{\circ} \mathrm{C}$. OHC and $T_{\overline{100}}$ can be qualitatively different also over shallow continental shelves: $\mathrm{OHC}$ will generally indicate comparatively low values regardless of the ocean temperature, while $T_{\overline{100}}$ will take on high values over a shelf that is warm and upwelling neutral or negative. In so far as the ocean thermal field alone is concerned, these warm, shallow continental shelves would appear to be as favorable for hurricane intensification as are warm, deep ocean regions.
\end{abstract}

\section{Hurricanes and the ocean}

Hurricanes draw energy from the ocean in the form of sensible and latent heat fluxes that result from very high wind speeds and a rather small temperature difference between the subtropical atmosphere and warmer sea surface, typically only a few ${ }^{\circ} \mathrm{C}$ (Emanuel, 1999). Hurricanes are known to cool the sea surface by anywhere from 1 to $4^{\circ} \mathrm{C}$ (Fig. 1; Leipper and Volgenau, 1972; Price, 1981; Zedler et al., 2002;
D'Asaro et al., 2007), locally, which is enough to reduce significantly or even reverse the hurricane-ocean temperature difference. This hurricane-induced cooling of the sea surface must reduce the hurricane-ocean heat flux and thus hurricane intensity to some degree (Bender et al., 1993; Schade and Emanuel, 1999; Cione and Uhlhorn, 2003). This paper considers the ways in which the ocean generally, and this phenomenon in particular, might be represented within a hurricane-ocean forecasting system.

\subsection{Observations, forecasts, and a hierarchy of ocean models}

The ocean component of a hurricane forecasting system can take one of several different forms. In the most comprehensive version, ocean initial (or present state) temperature (and salinity) data $T_{i}(x, y, z)$, here presumed given may be combined with a three-dimensional (3-D) ocean circulation and mixing model that may in turn be coupled to a highly resolved weather prediction model. These comprehensive, coupled air-sea models can be used to make detailed forecasts of specific storms (Ginis, 2002; Bender et al., 2007; Chen et al., 2007; Halliwell et al., 2008) and will soon be a primary forecast tool in some weather centers. Existing weather prediction models now make reasonably good forecasts of a hurricane track (Marks et al., 1998), which is dependent mainly upon the surrounding, large-scale wind field. The intensity of a given hurricane is by comparison much more difficult to forecast reliably, and, as suggested above, is likely to be dependent in part upon interaction between the hurricane and the underlying ocean.

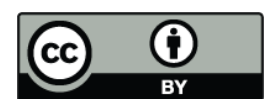

Correspondence to: J. F. Price

(jprice@whoi.edu)

Published by Copernicus Publications on behalf of the European Geosciences Union. 

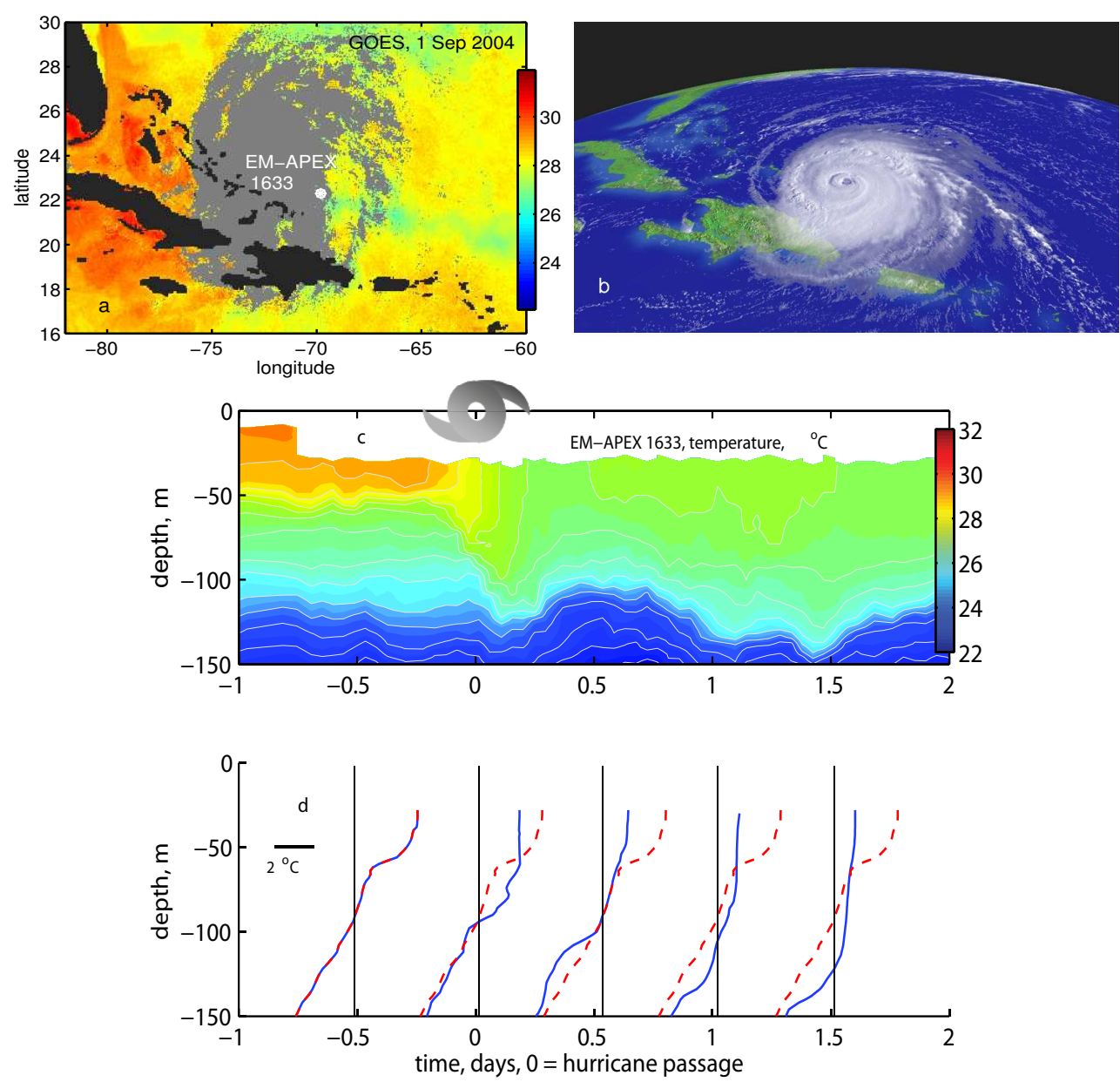

Fig. 1. Observations from CBLAST Hurricane Frances (2004) (see Black et al., 2007 for an overview of CBLAST). (a) GOES SST image of the subtropical western North Atlantic and Hurricane Frances (clouds are shown as a light gray mass) as it moved west north-west at 5 to $6 \mathrm{~m} \mathrm{~s}^{-1}$ over the site where EM-APEX floats had been air-launched one day before; the white asterisk denotes the position of float 1633 (Sanford et al., 2007). Notice that SST was higher ahead of Hurricane Frances (to the west), than behind. Within the coolest part of the wake, SST was reduced by about 2 to $3^{\circ} \mathrm{C}$ during the hurricane passage (see also D'Asaro et al., 2007 and Zedler et al., 2009). (b) A nearly simultaneous true color image, also from GOES. (c) Time-depth section of temperature measured by EM-APEX float 1633 . The color coding of temperature is the same in this section as in the SST map above. The hurricane symbol shows the approximate time during which wind speed exceeded $20 \mathrm{~m} \mathrm{~s}^{-1}$. The cloud shield seen in the images above was about twice this size. (d) The corresponding temperature profiles. The red dashed profile was observed before the hurricane passage and is repeated as a reference for subsequent profiles that are shown at half-day intervals. The shallowest measured temperature at $30 \mathrm{~m}$ depth decreased by about $2.3^{\circ} \mathrm{C}$, roughly consistent with the GOES SST image.

The emphasis of this paper will be mainly upon ocean models at the other extreme of complexity, in which the same initial ocean data and an understanding of the salient ocean mixing and thermodynamics are combined into a metric (DeMaria et al., 2005),

$M(x, y)=F\left(T_{i}(x, y, z), \ldots\right)$,

that, with appropriate interpretation, provides forecast guidance regarding hurricane-ocean interaction. The function $F$, which is the object of this paper, evaluates, integrates or averages over depth, $z$, to yield a two-dimensional, mappable variable, or metric. The ellipsis indicates that more than the thermal field alone is likely to be relevant. For any specific forecast, a forecast hurricane track is presumed to be available, and thus the relevant position(s) $(x, y)$ are presumed known.

One metric of this sort is the initial sea surface temperature,

$\operatorname{SST}_{i}(x, y)=T_{i}(x, y, z=0)$.

It is well known that $\mathrm{SST}_{i} \geq 26^{\circ} \mathrm{C}$ is a necessary condition for the formation of hurricanes (Miller, 1958; Tonkin et al., 2000 and references therein). Of course, we don't need (1) to help us find $\mathrm{SST}$, but $\mathrm{SST}_{i}$ is almost certainly not the entire story 
for hurricane-ocean interaction. It was noted at the beginning that SST cools significantly during a hurricane passage. Closely related is that $\mathrm{SST}_{i}$ is likely to be representative of only the upper few tens of meters of the water column and it is expected that hurricanes will interact with (very roughly) the upper $100 \mathrm{~m}$ of the ocean. The physical mechanism(s) of hurricane-ocean interaction and the depth over which interaction is appreciable are among the central issues for determining an appropriate $F$.

\subsection{Upper Ocean Heat Content, an integral of the ocean temperature}

The first ocean metric that took account of the subsurface ocean temperature, called upper Ocean Heat Content (OHC), was written down by Leipper and Volgenau (1972) almost forty years ago

$\mathrm{OHC}(x, y)=\rho_{o} C_{p} \int_{Z_{26}}^{0}\left(T_{i}(x, y, z)-26\right) d z$,

and is today widely used in operational, hurricane forecasting (Goni and Trinanes, 2003; DeMaria et al., 2005; and see especially the informative, recent review by Mainelli et al., 2008). The leading factors, $\rho_{o}=1025 \mathrm{~kg} \mathrm{~m}^{-3}$ and $C_{p}=4.0 \times 10^{3} \mathrm{~J} \mathrm{~kg}^{-1}{ }^{\circ} \mathrm{C}^{-1}$ are sea water density and heat capacity and the lower limit of integration is the depth of the $26^{\circ} \mathrm{C}$ isotherm, $Z_{26}$. The reference temperature, $26^{\circ} \mathrm{C}$, is an average (dry bulb) temperature in the subtropical atmospheric boundary layer and so $T_{i}(x, y, z=0)-26$ is a measure of the thermal disequilibrium between the atmosphere and the initial state of the ocean. Aside from $\rho_{o}$ and $C_{p}$, which are effectively constants, $\mathrm{OHC}$ has an obvious interpretation as how much (temperature $\times$ thickness) ocean temperature at a given $(x, y)$ exceeds the reference temperature, $26^{\circ} \mathrm{C}$, and expressed as a heat content. Notice that in the usual case that ocean temperature is monotonically increasing toward the surface, water having a temperature less than $26^{\circ} \mathrm{C}$ will make no contribution to $\mathrm{OHC}$. A consequence is that $\mathrm{OHC}$ can not show how far below the reference temperature the ocean temperature may be, an issue that arises in Sect. 3.1.2.

\footnotetext{
${ }^{1}$ The quantity defined by Eq. (3) has also been called hurricane heat potential (Leipper and Volgenau, 1972), and tropical cyclone heat potential (Goni and Trinanes, 2003). To the extent that "heat content" implies conservation properties, these might be better names (and see Warren (2006) on this common usage of "heat"). Conservation issues are of two kinds, roughly thermodynamic and fluid dynamic. OHC is not conserved under mixing because of changes in density and heat capacity. These errors are very small in the present context, but can be almost completely avoided by use of potential enthalpy (McDougall, 2003). A much bigger conservation error may arise from the lower limit of integration for $\mathrm{OHC}$, the depth of the $26^{\circ} \mathrm{C}$ isotherm, $Z_{26}$. In the presence of vertical mixing near $Z_{26}$, which occurs commonly (Fig. $1 \mathrm{~b}$ and c, and D'Asaro et al., 2007), this lower limit is not a material surface whose mo-
}

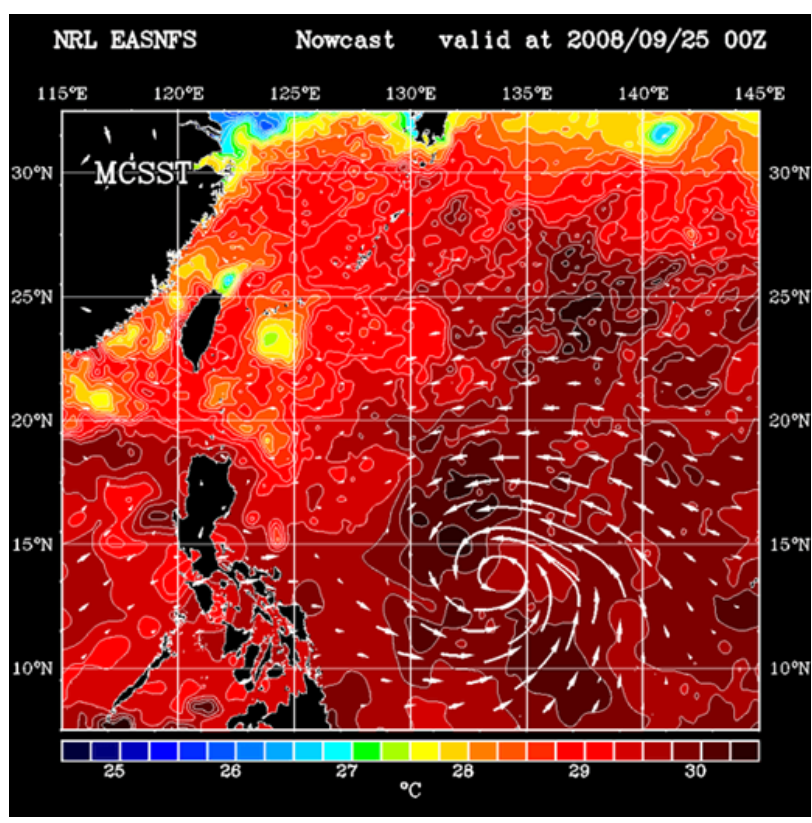

Fig. 2. A synoptic map of SST from the East Asian Seas Nowcast and Forecast System (EASNFS) of the Naval Research Laboratory (Ko et al., 2008) for 25 September 2008. The white vectors are low level wind.

OHC was not derived from theory so much as it was constructed ad hoc on the reasonable basis that if hurricaneocean heat exchange is important to a hurricane, then oceanic regions having larger or smaller heat content should be more or less favorable for hurricane formation or intensification (Leipper and Volgenau, 1972; hereafter just intensification). There will be a discussion of mechanisms beginning in Sect. 2, but for now we note that this has been verified, at least in the warm, deep ocean regime (summertime, open Gulf of Mexico) with which Leipper and Volgenau (1972) were most concerned.

tion would be connected by continuity with the surrounding fluid. To appreciate the consequence, imagine that vertical mixing within the ocean surface layer (no hurricane-ocean heat flux) acts to cool the surface layer, eventually below $26^{\circ} \mathrm{C}$. $\mathrm{OHC}$ will vanish as the surface layer cools below $26^{\circ} \mathrm{C}$ and the depth $Z_{26}$ moves upward through the sea surface. This decrease of $\mathrm{OHC}$ in a given column is not necessarily balanced by a gain at some other location in the domain; OHC may simply disappear as a result of sufficient vertical mixing and cooling of the surface layer. This non-conservation is not at issue for the interpretation of any single map of $\mathrm{OHC}$, but it can be pernicious when $\mathrm{OHC}$ is used in an analysis. For example, estimates of time-changing (usually decreasing) OHC during a hurricane passage may lead to overestimates of the magnitude of the inferred hurricane-ocean heat exchange, even if vertical and horizontal advection are accounted appropriately. The phrase 'upper ocean heat content' has also been used in large-scale ocean climate contexts to mean the temperature integral over the (fixed) upper $750 \mathrm{~m}$ of the ocean (Willis et al., 2004). 


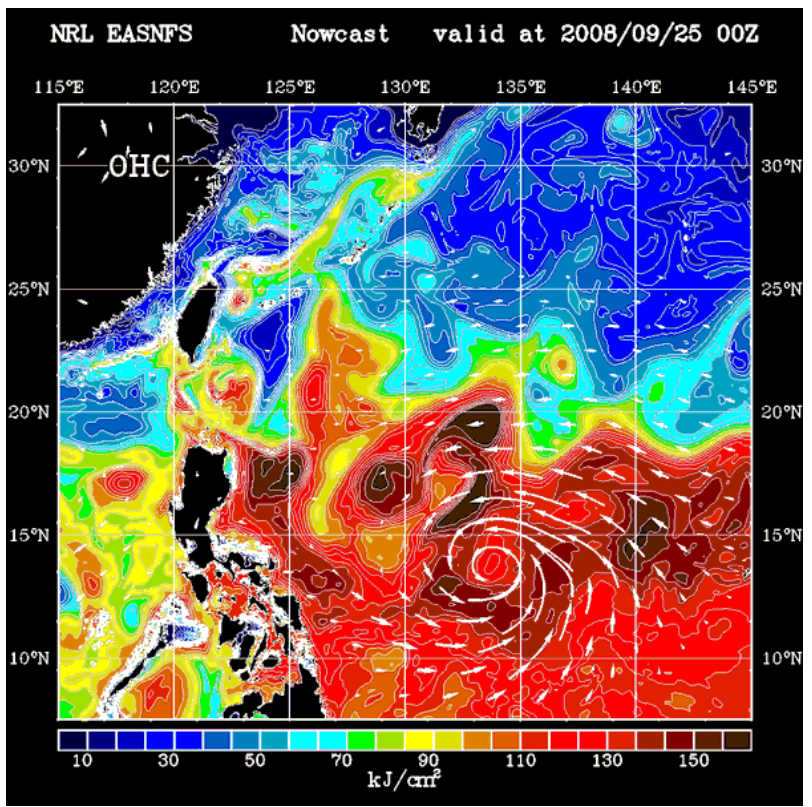

Fig. 3. A synoptic map of OHC computed by the EASFNS. The corresponding SST was in the previous figure. Note that the largest values of $\mathrm{OHC}$ are found along the axis of the subtropical gyre, roughly $17^{\circ} \mathrm{N}$ west of Luzon, and especially in mesoscale patches that correspond to relative highs of the sea surface height (about $20 \mathrm{~cm}$ amplitude). Uniformly low values of $\mathrm{OHC}$ are estimated along the northern boundary of this region, and also along the wide, shallow continental shelf south and east of China.

OHC takes on the largest values, $\mathrm{OHC} \geq 100 \mathrm{~kJ} \mathrm{~cm}^{-2}$, over oceanic regions having a comparatively warm, thick surface layer, often in association with a subtropical gyre interior or an associated western boundary current system, the Kuroshio or the Gulf of Mexico's Loop Current (Shay et al., 2000; Halliwell et al., 2008) being important examples. A significant correlation between these high OHC features and hurricane intensification has been found in late summer conditions in which the pre-hurricane SST field is often quasiuniform horizontally (Figs. 2 and 3). Extensive testing and forecasting experience has thus shown that high range $\mathrm{OHC}$, roughly $\mathrm{OHC} \geq 60 \mathrm{~kJ} \mathrm{~cm}^{-2}$, provides significant information on the ocean thermal field beyond that provided by the $\mathrm{SST}_{i}$ field alone (Goni and Trinanes, 2003; Scharoo et al., 2006; McTaggart-Cowan et al., 2007; Lin et al., 2008; Mainelli et al., 2008; see also Sun et al., 2006).

There are also observations that do not fit comfortably within an OHC framework. At one level anomalies are not surprising; ocean thermal conditions, no matter how they are represented, are not the sole nor necessarily the most important determinant of hurricane intensity. Large-scale wind and humidity distributions are at least as important, and internal variability occurs within hurricanes on small spatial and time scales that are very difficult to predict (Marks et al., 1998). One notable, apparent anomaly has real consequences for

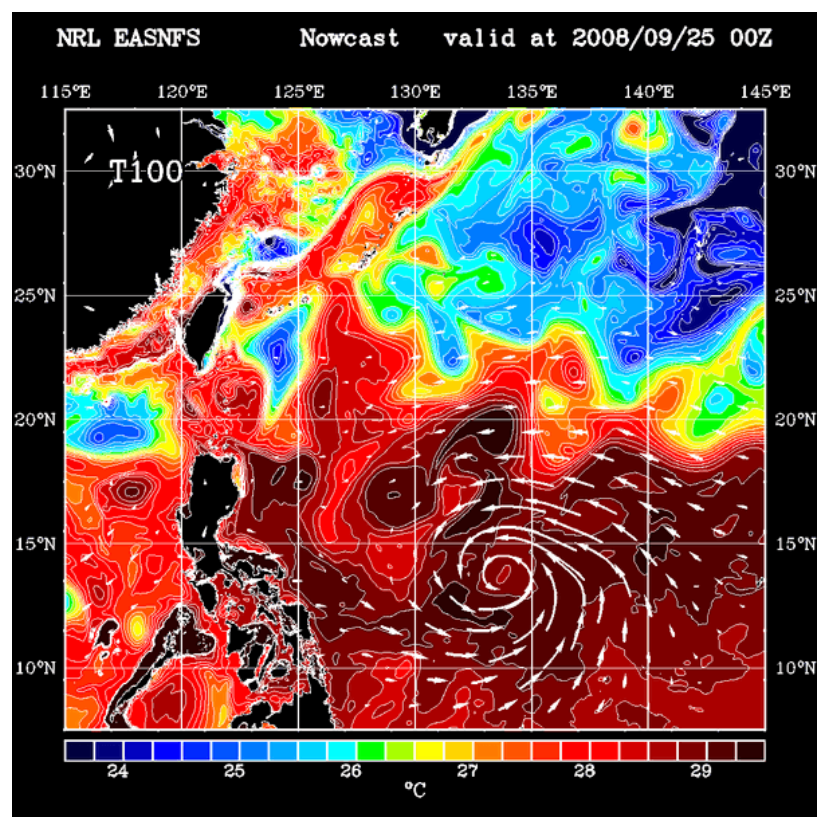

Fig. 4. A map of $T_{\overline{100}}$, the ocean temperature averaged over the upper $100 \mathrm{~m}$ or to the ocean bottom (introduced in Sect. 2.2) computed by the EASNFS of the Naval Research Laboratory. This map was computed on the same ocean temperature field as was OHC of Fig. 3 and may be compared directly. The highest values of OHC and $T_{100}$ corresponding to the subtropical gyre ridge along $15^{\circ} \mathrm{N}$ are similar in shape in these maps. The low values are in some respects quite different, especially along the southeastern coast of China; OHC indicates low values simply because of shoaling water depth, where $T \overline{100}$ indicates fairly high values within a coastal warm boundary layer (defined in Sect. 3.2.2) that is up to several hundred kilometers in width. This map was kindly provided by Dr. Dong-Shan Ko of the Naval Research Laboratory.

forecasting, viz., the correlation between hurricane intensity and high range $\mathrm{OHC}$ noted above disappears within the low range of $\mathrm{OHC}, 0 \leq \mathrm{OHC} \leq 60 \mathrm{~kJ} \mathrm{~cm}^{-2}$. Thus, while high values of $\mathrm{OHC}$ are found to favor hurricane intensification, low values of $\mathrm{OHC}$ are found to have no significant, consistent effect, either positive or negative. Low range $\mathrm{OHC}$ is therefore excluded from some forecast and analysis schemes (Mainelli et al., 2008). This loss of correlation between hurricane intensity and low range $\mathrm{OHC}$ is considered in some detail in Sects. 3.1.2 and 3.2.1. The upshot will be that $\mathrm{OHC}$ does not bear a consistent relationship to SST in cool, deep ocean conditions or in shallow water and so OHC would not be expected to be a useful metric in those common conditions. To be fair to Leipper and Volgenau (1972), this critique amounts to applying OHC outside of the warm, deep ocean conditions that they envisioned. However, maps of $\mathrm{OHC}$ (Goni and Trinanes, 2003) and statistical analyses using $\mathrm{OHC}$ as the ocean metric (DeMaria et al., 2005; Mainelli et al., 2008) necessarily include all oceanic regions where hurricanes occur, and not excluding regions with small or vanishing $\mathrm{OHC}$. Thus 
the parameter space of cool SST and shallow water is unavoidable in a discussion of ocean metrics that are intended for more than a qualitative interpretation, the intent here.

\subsection{The goal and the plan of this paper}

The object of the present work is a new, rationalized ocean metric for use within a hurricane-ocean forecasting or analysis scheme. The scope of this paper is limited to the ocean half of hurricane-ocean interaction, and the approach will be to build upon the extensive history of $\mathrm{OHC}$ reviewed above, while also making use of 3-D ocean models and guidance from ocean process field studies that were unavailable when $\mathrm{OHC}$ was proposed. The starting point is a review of the mechanisms that cause sea surface cooling during a hurricane passage, Sect. 2.1. This leads to the hypothesis that a vertical average of upper ocean temperature is a more relevant metric than is OHC, a vertical integral of ocean temperature, Sect. 2.2. The consequences of averaging vis-a-vis integrating are explored in Sect. 3; Sect. 3.1 considers the deep, open ocean, and Sect. 3.2 considers a continental shelf. A summary of the present results and remarks on future research are in the concluding Sect. 4.

\section{The oceanic mechanisms of hurricane-ocean interac- tion}

Heat content is not a substance that is transferred from the ocean into the atmosphere simply by contact. And specifically, high $\mathrm{OHC}$ does not by itself insure that there will be a high heat flux from the ocean into a hurricane. A thermal disequilibrium (temperature and humidity difference) between the sea surface and the lower atmosphere must be involved as an intermediary, and all else equal, the larger this disequilibrium, the larger the heat flux. The oceanic part of this is the SST. The route to a new ocean metric begins from this point of view and then requires just three premises. Premise 1, which more or less summarizes the point made just above, is that

P1: The relevant oceanic property for hurricaneocean interaction is SST and especially the SST underneath a hurricane.

Subsurface ocean temperature (and by extension, OHC) may be very important indirectly, but only to the extent that it effects the SST. The SST underneath a hurricane is singled out in $\mathrm{P} 1$ because it corresponds with the high wind speed, central region of a hurricane and thus the greatest potential for heat exchange (Cione and Uhlhorn, 2003). (P1 seems to elide a role for the other important property of the sea surface, sea state, out of ignorance rather than conviction.) The second premise follows closely on $\mathrm{P} 1$.

P2: An oceanic region will be regarded as favorable for hurricane intensification if the initial SST is high and if the SST remains high during a hurricane passage.

SST should be considered high or low with respect to the atmosphere just above; absent specific observations, $26^{\circ} \mathrm{C}$ is a reasonable reference. Assuming that the initial temperature field $T_{i}(x, y, z)$ is given, then the oceanic part of hurricaneocean forecasting amounts to predicting the cooling of SST that occurs under a hurricane (taking the hurricane perspective, as is implicit in Fig. 1a) or during a hurricane passage (from the ocean perspective, Fig. 1c).

\subsection{Sea surface cooling mechanisms}

The sea surface underneath a hurricane is cooled by two distinct mechanisms - by hurricane-ocean heat exchange noted above, and by vertical, turbulent mixing of cooler water upward into the surface layer (Price, 1981; Jacob et al., 2000; D'Asaro et al., 2007). If the hurricane-induced sea surface cooling noted above was due mainly to heat exchange, then OHC would be an appropriate metric for representing the ocean thermal field. However, two lines of evidence appear to suggest otherwise. Leipper and Volgenau (1972) noted that the large values of OHC found over much of the deep, subtropical oceans are far in excess of the time-integrated heat flux to a given hurricane, often by a factor of 10 or more (noted also by Cione and Uhlhorn, 2003 and by Mainelli et al., 2008). In a later Sect. 3.2, the time-integrated (net) heat flux (sum of latent and sensible fluxes) to a single hurricane is estimated as $Q_{\text {net }} \approx 5 \times 10^{7} \mathrm{~J} \mathrm{~m}^{-2}=5 \mathrm{~kJ} \mathrm{~cm}^{-2}$ (Fig. 5). This net heat flux will cool a water column that is $100 \mathrm{~m}$ thick by about only about $0.12^{\circ} \mathrm{C}$, and a $10 \mathrm{~m}$-thick column by about $1.2^{\circ} \mathrm{C}$ (Fig. 5). Thus, even a rather shallow, warm continental shelf will have greater heat content, as estimated by $\mathrm{OHC}$, than will be absorbed by a single hurricane. On this basis alone it seems unlikely that $\mathrm{OHC}$ per se sets a significant limit on hurricane-ocean interaction (aside from the case of very shallow water environments). This does not preclude that $\mathrm{OHC}$ may nevertheless serve as an effective metric for the ocean thermal field in some specific conditions, viz., the warm, deep ocean conditions emphasized by Leipper and Volgenau (1972) (Sect. 3.1.1).

A number of subsequent, upper ocean field studies and model studies have found that the primary mechanism that cools the sea surface during a hurricane passage is turbulent, vertical (diapycnal) mixing (Price, 1981; Bender et al., 1993; Jacob et al., 2000; Sanford et al., 2007; D'Asaro et al., 2007). The evidence of this is that the sea surface may cool significantly without there being an appreciable change in the upper ocean heat content (suitably chosen, footnote 1). The temperature profiles of Fig. 1d are an example; during the passage of Hurricane Frances (2004) the surface temperature cooled by about $2.3^{\circ} \mathrm{C}$ as the temperature profile became quasi-homogeneous over very roughly the upper $100 \mathrm{~m}$. A comparison of pre- and post-hurricane temperature profiles 

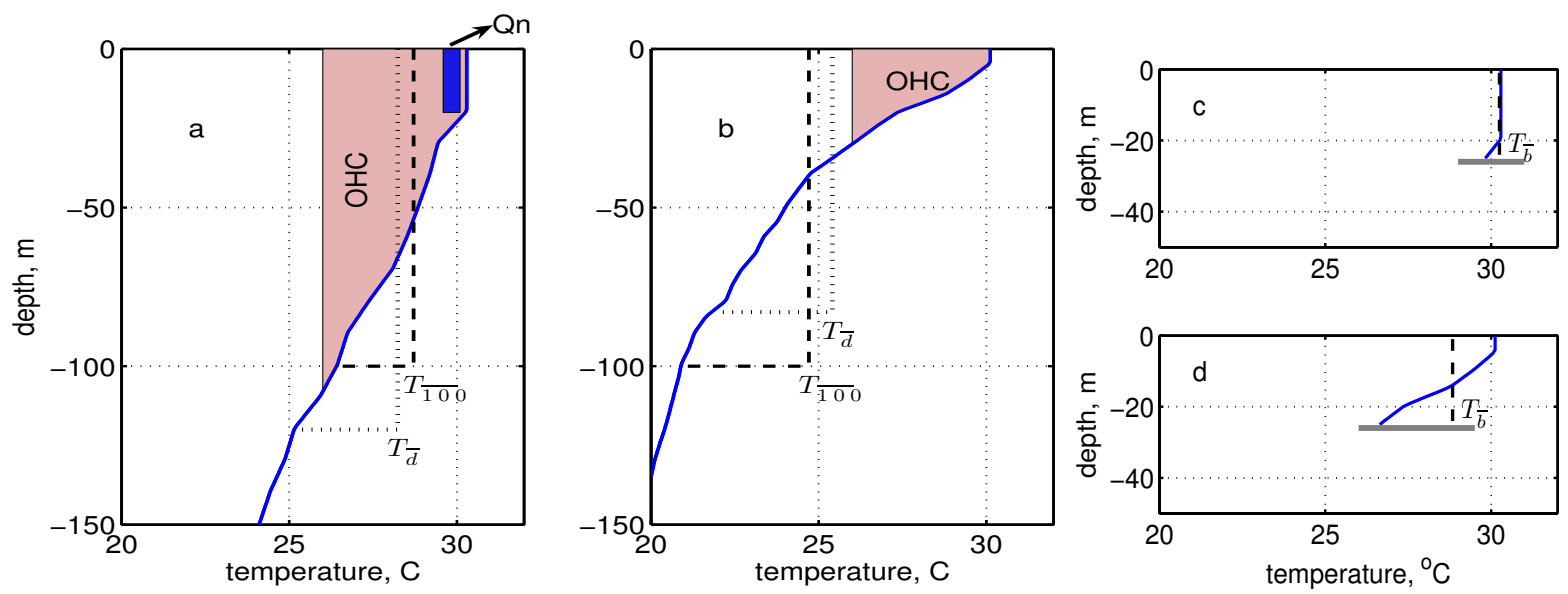

Fig. 5. Deep, open ocean Argo float temperature profiles from the western, subtropical North Pacific, both of which have SST $\approx 30^{\circ} \mathrm{C}$. These two profiles are rather extreme examples of a deep thermocline and a thick surface layer, profile (a) at left, and a shallow thermocline and thin surface layer, profile (b) at right. OHC is proportional to the lightly shaded area and thus more or less proportional to the thermocline depth. The much smaller, darker shaded area near the surface in (a) is proportional to an estimate of the net hurricane-ocean heat exchange, $Q_{n} \approx 5 \mathrm{~kJ} \mathrm{~cm}^{-2}$ (Sect. 3.2.2). The dashed line labeled $T \overline{100}$ is the temperature profile after vertical mixing to a depth of $100 \mathrm{~m}$, a typical depth of mixing by a category 3 hurricane (Sect. 2.2.1). Note that mixing to $100 \mathrm{~m}$ cools the sea surface of profile (a) by only about $1.5^{\circ} \mathrm{C}$ because the water that was mixed upward into the surface layer was only slightly cooler than the water present above $z=-100 \mathrm{~m}$. Either ocean metric, OHC or $T_{\overline{100}}$, would indicate that temperature profile (a) is favorable for hurricane intensification. In profile (b), the cooling effect of the same vertical mixing is much greater, $\approx 5^{\circ} \mathrm{C}$, and notice that $\mathrm{OHC}$ is also much smaller; both ocean metrics would indicate that profile (b) is not favorable (or comparatively less favorable) for intensification than is profile (a). The dotted lines labeled $T_{\bar{d}}$ are the temperature profiles after vertical mixing from the surface to a depth of $d=120 \mathrm{~m}$ (a) or $d=85 \mathrm{~m}$ (b) (why these depths is discussed in Sect. 2.2.2). (c) and (d) The profiles from (a) and (b) but with a shallow bottom indicated at (arbitrarily) $25 \mathrm{~m}$; discussed in Sects. 3.2 and 4.1.

shows that the net cooling (temperature change times thickness) caused by vertical mixing within the upper ocean is approximately equal in magnitude to the net warming caused by vertical mixing in the upper thermocline (this warming is not of direct interest here, but may have relevance over climate time scales, see Sriver and Huber, 2008). Detailed studies of the upper ocean heat budget have found that the ratio of the heat flux due to vertical mixing compared to the hurricane-ocean heat exchange is $\mathrm{O}(10)$ in deep water cases (Jacob et al., 2000; Cione and Uhlhorn, 2003; D'Asaro et al., 2007), consistent with the observations noted above. The principle mechanism on the ocean side of hurricane-ocean interaction can then be summarized in Premise 3 - while hurricane-ocean heat exchange may be very important to a hurricane, nevertheless

P3: The large amplitude, $1-4^{\circ} \mathrm{C}$, cooling of the sea surface that occurs during a hurricane passage is due mainly to vertical mixing of cooler water into the ocean surface layer.

\subsection{A new ocean metric, depth-averaged temperature}

Given P1-P3, it follows that a metric intended to represent the ocean thermal field should account first of all for the sea surface cooling effect of vertical mixing (caused mainly by the very high winds of a hurricane) and only secondarily for hurricane-ocean heat exchange. Vertical mixing is equivalent to vertical averaging, and this leads to the hypothesis advanced in this paper:

H1: The appropriate ocean thermal metric for hurricane-ocean interaction is a vertical average of the initial (pre-hurricane) ocean temperature,

$$
T_{\bar{d}}(x, y)=\frac{1}{d} \int_{-d}^{0} T_{i}(x, y, z) d z
$$

where $d$ is the depth of vertical mixing caused by a hurricane, i.e., the surface mixed-layer thickness.

The depth $d$ has to be predicted or specified if $T_{\bar{d}}$ is to be predicted, and two methods for doing that are discussed below. If, as will be presumed here, $d$ is evaluated in the wake of a hurricane, then the resulting depth-averaged temperature, $T_{\bar{d}}$, is an estimate of the mixed-layer temperature in the wake.

Given that SST decreases during a hurricane passage, the interpretation of $T_{\bar{d}}$ is straightforward. High values of $T_{d}$, say $T_{\bar{d}} \geq 28^{\circ} \mathrm{C}$, would indicate even slightly higher SST during a hurricane passage and thus an ocean thermal field that is favorable for hurricane intensification (on the basis that SST remains several degrees above $26^{\circ} \mathrm{C}$ ). On the other hand, low 
values, say $T_{\bar{d}} \leq 24^{\circ} \mathrm{C}$, would indicate low values of SST during a hurricane passage, and so an ocean thermal field that was comparatively unfavorable (or much less favorable) for intensification.

The dependence of sea surface cooling upon upper ocean stratification is the key property of a depth-averaged temperature metric. For example, if there is a comparatively small temperature (vertical) contrast in the water column above $z=-d$ that is mixed vertically, as in profile (a) of Fig. 5, then vertical mixing will cause comparatively little cooling of the sea surface. If the ocean bottom is shallow and the bottom temperature is warm (Fig. 5c) then, perforce, vertical mixing will cause very little cooling of the sea surface.

The issue now turns to estimation or prediction of $d$. At some risk of confusion there are two versions of $d$ suggested here. The first is a very simple, empirical, fixed- $d$ version that is based upon the CBLAST field observations of Fig. 1c and Fig. 1d and that serves the most important purpose of this paper - to contrast integrated and averaged ocean temperatures. There follows a more complex and more capable variable- $d$ version that takes account of the spatiallyvariable density stratification of the initial ocean and allows for stronger or weaker hurricanes. This variable- $d$ version is better suited for forecasting purposes.

\subsubsection{Fixed depth, $d=100 \mathrm{~m}$ and $T_{\overline{100}}$}

The simplest, plausible version of $d$ is to take a fixed value, $d=100 \mathrm{~m}$, or to the ocean bottom, if that is shallower. The choice $d=100 \mathrm{~m}$ is admittedly a round number, but is consistent with the observed depth of vertical mixing under Hurricane Frances (2004) a category 3-4 hurricane used here as the base case (by inspection of Fig. 1c and d; see also Sanford et al., 2007 and D'Asaro et al., 2007). The corresponding, depth-averaged temperature computed from Eq. (4) is dubbed $T_{\overline{100}}$ (Figs. 4 and 5).

The depth of vertical mixing and the associated SST cooling vary significantly in the direction perpendicular to a hurricane track; $100 \mathrm{~m}$ is the maximum depth of vertical mixing, usually found about $30-70 \mathrm{~km}$ to the right of the track of a hurricane moving at a typical speed, $5 \mathrm{~m} \mathrm{~s}^{-1}$ (Fig. 1a). A map $T_{\overline{100}}(x, y)$ (Fig. 4) is then the minimum SST expected in a hurricane wake, and not the map for a single hurricane, as in Fig. 1a. The minimum temperature (maximum depth of mixing) was chosen because it is the least ambiguous SST to observe and is the SST that is most frequently cited, e.g., the cooling values of Sect. 1. Whether this depth-averaged temperature is the most appropriate SST for hurricane-ocean interaction, vs. say the SST under the eye (Cione and Uhlhorn, 2003), is considered on closing in Sect. 4.3.

$T \overline{100}$ has the advantage of great simplicity; it follows from $\mathrm{P} 1, \mathrm{P} 2$ and $\mathrm{P} 3$ and the observation $d=100 \mathrm{~m}$ with no model required. A comparison of $T_{\overline{100}}$ with $\mathrm{OHC}$ is sufficient to expose the similarities and the differences between a depthaveraged and a depth-integrated temperature, and so $T \overline{100}$ is emphasized up through Sect. 3.1. However, $T_{\overline{100}}$ is almost certainly not the best possible depth-averaged temperature for forecasting purposes because mixing to a depth of $100 \mathrm{~m}$ is by no means universal. Given an especially stable density stratification (profile b of Fig. 5 or by virtue of a fresh surface layer) or given a minimal hurricane, the depth of mixing may be considerably less.

\subsubsection{Variable depth $d$ and $T_{\bar{d}}$}

These and other external factors can be accounted by an ocean mixing model that estimates $d$ at each point $(x, y)$. The variable- $d$ metric suggested here requires a good deal more data than does $T_{\overline{100}}$; the density profile, $\rho(z)$, which will in general require temperature and salinity profiles, as well as a few key pieces of data describing the hurricane of interest. Here we presume Hurricane Frances (2004) (Sanford et al., 2007): radius to maximum winds, $R_{h}(35 \mathrm{~km})$, translation speed, $U_{h}\left(5.5 \mathrm{~m} \mathrm{~s}^{-1}\right)$, and the maximum wind stress, $\tau(5.5 \mathrm{~Pa})$. A variable- $d$ metric also requires a parameterization to connect vertical, turbulent mixing in the upper ocean with the hurricane forcing. The parameterization applied here is that the bulk Richardson number of the surface mixed-layer should not be less than a critical value, $C=0.6$ (Price, 1981),

$$
\frac{g \delta \rho d}{\rho_{0}(\delta U)^{2}} \geq C
$$

or,

$$
\frac{g\left[\rho(z=-d)-\frac{-1}{d} \int_{0}^{-d} \rho(z) d z\right] d}{\rho_{0}\left(\frac{\tau}{\rho_{o} d} \frac{4 R_{h}}{U_{h}} S\right)^{2}} \geq 0.6,
$$

where $g$ is the acceleration of gravity. The operator $\delta$ takes the difference between the surface mixed-layer and the value just below, as if there was a jump in density and velocity. The wind-driven current that appears in the denominator of the Richardson number, $\delta U$, has been estimated as the product of the wind stress-induced acceleration, $=\tau / \rho_{o} d$, and the hurricane residence time, $4 R_{h} / U_{h}$. The effects of Earth's rotation and the rotation in time of hurricane wind stress are not treated explicitly. An ad hoc similarity "constant" $S$ is therefore required to calibrate this scale estimate with 3-D numerical ocean model solutions made with a two-dimensional, translating hurricane wind stress field. The value of $S$ depends upon the cross-track coordinate, $y$. In keeping with the decision to estimate the maximum mixing and cooling, $S$ is evaluated at $y=55 \mathrm{~km}$ to the right of the track of Hurricane Frances (see Fig. 4 of Sanford et al., 2007) and is $S=1.2$. For comparison, at $55 \mathrm{~km}$ to the left of the track, $S=0.4$. This right-to-left variation of $S$ reflects the partial resonance of the rotating wind and wind-driven current on the right side of a hurricane track compared with the left. This calibration of $S$ is the first, specific way in which a 3-dimensional numerical ocean model has been used to develop an ocean metric. A second way is that the many simplifications inherent in this 
variable- $d$ metric - omission of all advection, pressure gradients and air-sea heat exchange, the specific value of $S-$ can be checked by comparing the resulting depth-averaged temperature, $T_{\bar{d}}$, against much more comprehensive, 3-D numerical ocean model solutions. The comparison is generally favorable, though with some reservations about the low $U_{h}$ limit (for details see the Supplementary Material noted at the end of this manuscript).

Given a density profile that is discretized at intervals $\Delta z$, Eq. (5) can be solved very quickly. The left hand side (lhs) of is evaluated with $d=n \Delta z$ from the surface downwards, i.e., with $n$ increasing from 1 . The $l h s$ starts with very low values, and is a monotonically increasing function of $n$ (assuming that density increases with depth). The equation is considered solved for $d$ when $l h s \geq C$, or when $n \Delta z=b$, where $b$ is the bottom depth and mixing is of course terminated. Once Eq. (5) has been solved for $d$, the corresponding depthaveraged temperature, $T_{\bar{d}}$, is then estimated by the vertical average, Eq. (4), evaluated over the given initial temperature profile, $T_{i}$ (from here on $d$ and $T_{\bar{d}}$ have this specific meaning). (The Matlab script used to evaluate $d$ and $T_{\bar{d}}$ on this Argo data is included in the Supplementary Material available online.)

Notice that the denominator of the Richardson number, Eq. 5, depends only upon hurricane parameters that are presumed known and would presumably be fixed for the evaluation of a given map. The numerator depends only upon the pre-hurricane ocean density profile and will likely vary regionally. The regional variation in a map of $T_{\overline{100}}$ or $T_{\bar{d}}$ (Fig. 4) thus reflects the regional variation of the ocean temperature and salinity (density) field and, where mixing reaches the bottom, the bottom depth.

\section{The comparative geography of $\mathrm{OHC}, T_{\overline{100}}$ and $T_{\bar{d}}$}

On first sight, the prescription for a depth-averaged temperature via Eq. (4) and the heat content computed via Eq. (3) do not look all that different, and in important and common circumstances (summer, subtropical, deep ocean) they will give essentially the same forecast guidance. In other circumstances they may be quite different. A corollary of $\mathrm{H} 1$ is that a depth-averaged temperature will make a useful ocean metric over a much wider range of conditions than does $\mathrm{OHC}$, a depth-integrated temperature. A full test of this important corollary is beyond the scope of this paper. What we can do here usefully is learn where and how OHC and the depthaveraged temperature will differ. To this end, both kinds of metrics have been evaluated using observations from the deep, open ocean (Sect. 3.1) and from an idealized continental shelf (Sect. 3.2). Salinity effects are then noted very briefly in Sect. 3.3.

\subsection{The deep ocean}

Two open ocean regions were considered; the first was a 20 by 20 degree region of the western subtropical North Pacific centered on $20^{\circ} \mathrm{N}$ and $130^{\circ} \mathrm{E}$ that was studied by Lin et al. (2008). The available Argo temperature and salinity profiles were acquired for the months July through October of 2007 (846 profiles in total, Fig. 6a). This region spawns some of the largest and most intense hurricanes (super typhoons) found anywhere in the world, and it is also a region having quite pronounced variability of the ocean mesoscale (Qiu, 1999). Eddies having a diameter of several hundred kilometers and sea surface height anomalies of $\pm 20 \mathrm{~cm}$ are common. These mesoscale eddies are accompanied by a raised or depressed thermocline (Fig. 5) and thus by substantial variations of OHC and $T_{100}$ that are not reflected in sea surface temperature (Fig. 6b, and compare Figs. 2 and 3 and Figs. 2 and 4). As noted already, Lin et al. (2008) found that the intensification of the most intense super typhoons is spatially correlated (coincident) with warm eddies (depressed thermocline) that show up as regions of especially high OHC (see Halliwell et al., 2008 for a discussion of mesocale variability in the Gulf of Mexico).

The second open ocean region considered here was the equivalent from the western North Atlantic, $10-30^{\circ} \mathrm{N}$, and $280-320^{\circ}$ and for the same months of 2007. These North Atlantic data (and a few profiles from the Caribbean Sea, 697 profiles total) are almost indistinguishable from the North $\mathrm{Pa}-$ cific data, the only difference being fewer points in the range of very large OHC (Fig. 6c and d). Within both data sets there are no doubt many profiles that were significantly effected by a typhoon or a hurricane. There was no attempt to sort these out, and all of the Argo profile data were treated as if they were initial data for the next storm.

Over these deep, open ocean regions, $T_{\overline{100}}$ and $T_{\bar{d}}$ are highly correlated and approximately equal (Fig. 7a and c). This means only that $d=100 \mathrm{~m}$ is not a bad approximation to the variable $d$ computed from Eq. (5) for each profile and for a typical category 3-4 hurricane. Nevertheless there is some variation of the estimated $d$ within this sample: $d$ was as large as $135 \mathrm{~m}$ on the most weakly stratified profiles (profile (a) of Fig. 5), and so $T_{\bar{d}}$ is slightly cooler than $T_{\overline{100}}$ in the range of cool temperatures; $d$ was as small as $85 \mathrm{~m}$ on the profiles that are most strongly stratified (profile (b) of Fig. 5), but the resulting $T_{\bar{d}}$ are not greatly different from the fixeddepth version, $T_{\overline{100}}$. We note here and again in Section 3.3 that this may not be the case in regions where salinity makes an appreciable contribution to the static stability of the upper ocean, and it would certainly not be the case if the storm of interest was a developing tropical depression vs. Hurricane Frances (2004). 

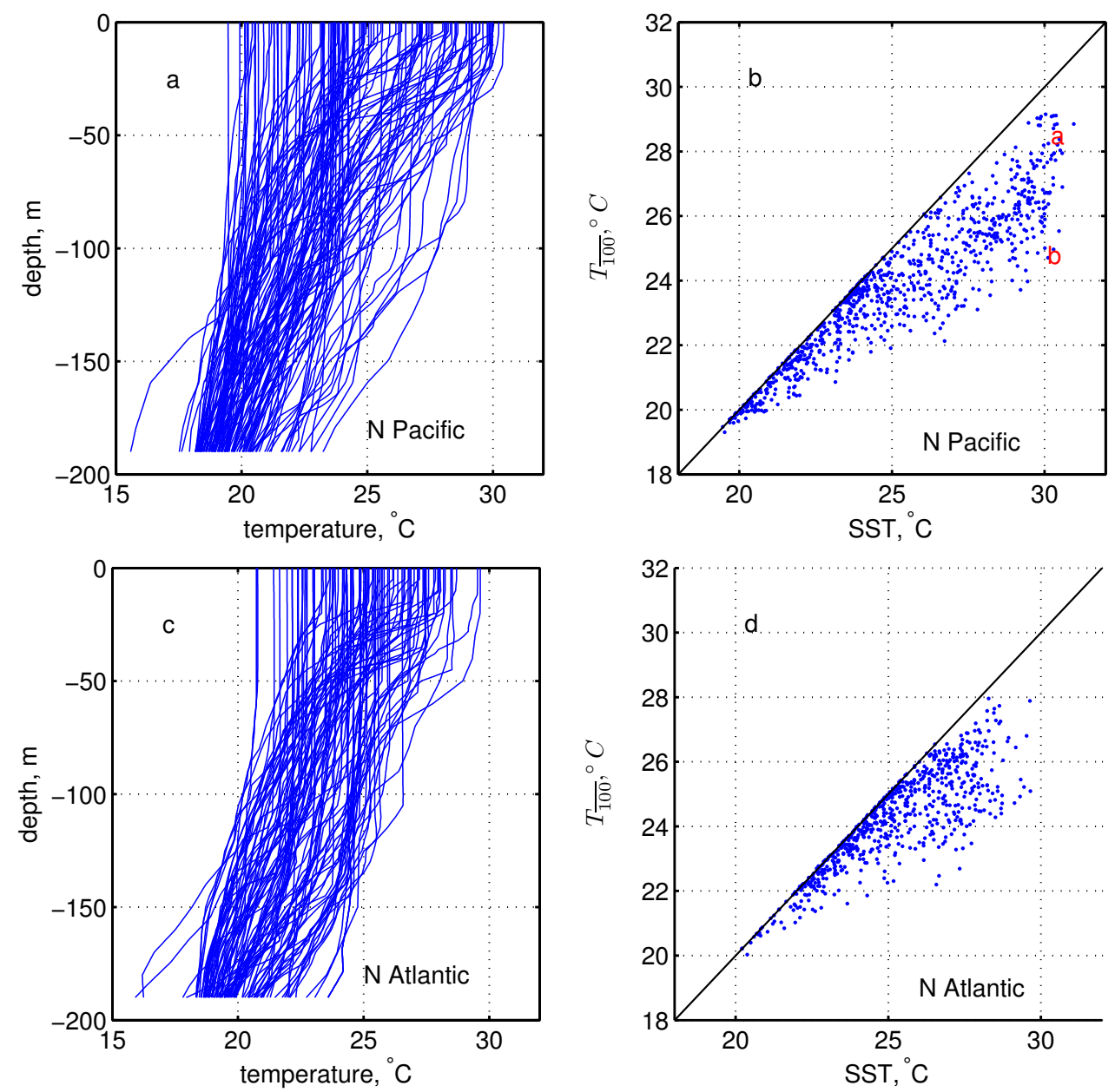

Fig. 6. Deep, open ocean Argo float profiles used to evaluate the metrics. (a) Argo temperature profiles from the western subtropical North Pacific (every seventh profile of 846 total; salinity not shown). The region sampled was centered on $20^{\circ} \mathrm{N}$ and $130^{\circ} \mathrm{E}$ and included June through October of 2007. (b) Sea surface temperature (SST; the shallowest measured temperature in an Argo profile) and the depth-averaged

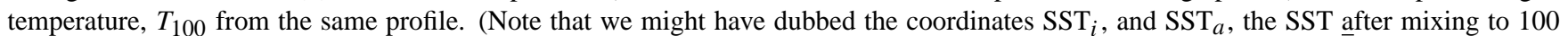
$\mathrm{m}$ depth.) The distance a point falls below the 1-to- 1 line is the cooling caused by mixing to $100 \mathrm{~m}$. The red letters "a" and " $\mathrm{b}$ " denote the (SST, $T_{100}$ ) of the profiles of Fig. 5a and b, respectively. (c) Argo temperature profiles from the western subtropical North Atlantic, same time period and 697 profiles in total. (d) SST and $T_{\overline{100}}$ from the western North Atlantic.

\subsubsection{Warm oceans and the high range of $\mathrm{OHC}$}

Both of the depth-averaged temperatures are closely related to $\mathrm{OHC}$ in the high range of $T_{\overline{100}}, T_{\overline{100}} \geq 27^{\circ} \mathrm{C}$ and $\mathrm{OHC}$, $\mathrm{OHC} \geq 75 \mathrm{~kJ} \mathrm{~cm}^{-2}$ (Fig. $7 \mathrm{~b}$ and d). It is not surprising that an especially warm, thick surface layer will indicate high values of OHC, $T_{\overline{100}}$ and $T_{\bar{d}}$ alike. What is not obvious is that the relationship between high range $\mathrm{OHC}$ and high $T \overline{100}$ appears to be very tight, bijective (one to one), and nearly identical in the western North Pacific and western North Atlantic. Within a given map, the contour lines of high $T_{\overline{100}}$ are essentially parallel with contour lines of high OHC (compare Figs. 3 and 4 over the subtropical gyre). Thus, high values of $T \overline{100}$ are expected to bear the same qualitative, spatial cor- relation with hurricane intensification as do high values of OHC (Lin et al., 2008; Shay et al., 2000; Mainelli et al., 2008). A depth-averaged temperature, either $T_{\overline{100}}$ or $T_{\bar{d}}$, thus repeats the most useful, demonstrated property of $\mathrm{OHC}$, i.e., high values of $T_{\overline{100}}$, roughly $T_{\overline{100}} \geq 27^{\circ} \mathrm{C}$, will identify open ocean regions where the thermal field is especially favorable for hurricane intensification. This was not accommodated after the fact, but follows straightforwardly from the definition of a depth-averaged temperature, Eq. (4), and the empirical relation between high range $\mathrm{OHC}$ and $T_{\overline{100}}$ seen in these data (Fig. 7b and d).

Indeed, the relation between high-range $\mathrm{OHC}$ and $T \overline{100}$ is so tight that if only warm, deep ocean conditions were relevant, then there would be very little practical motive to 

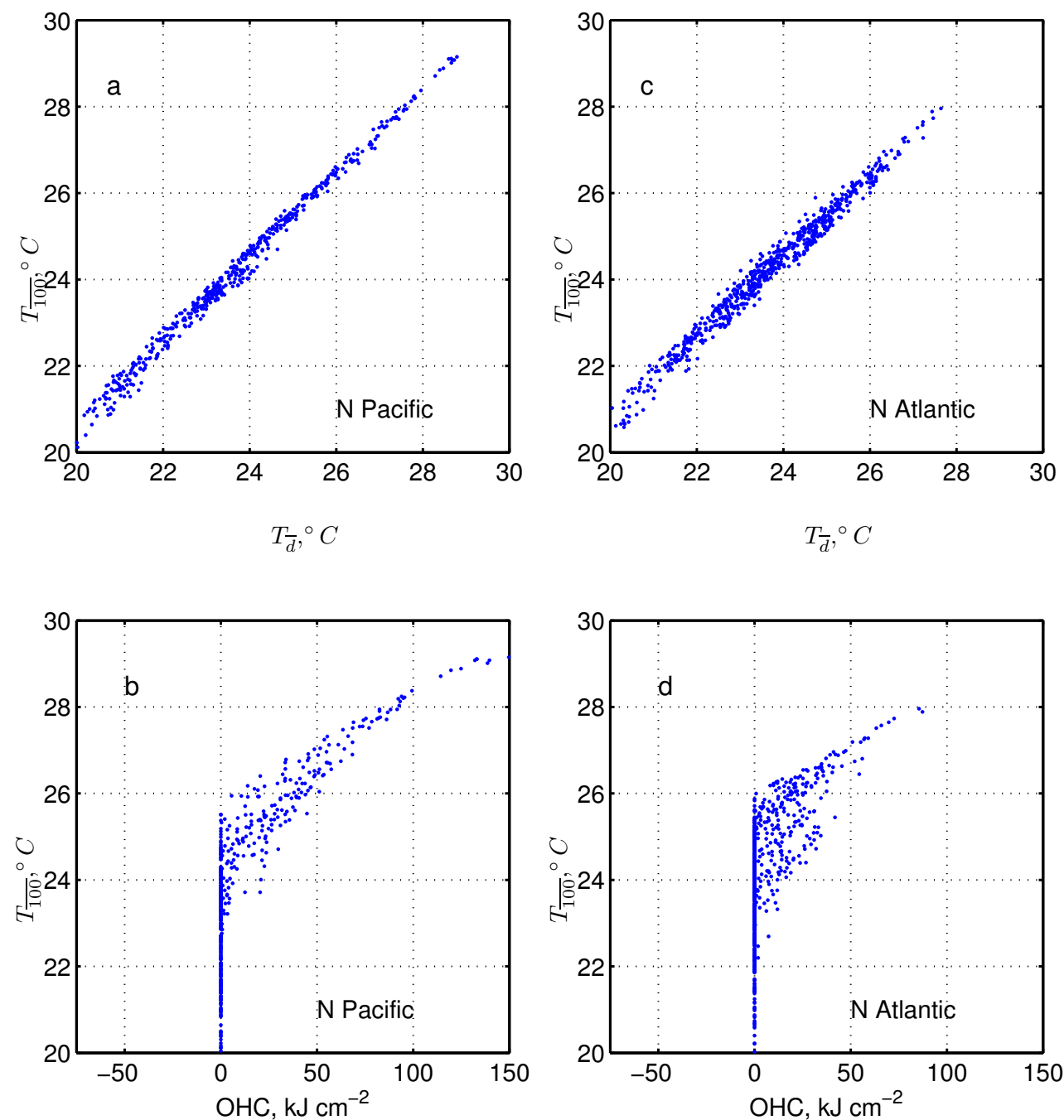

Fig. 7. Scatter diagrams of the ocean metrics. (a) The vertically-averaged temperatures, $T \overline{100}$ and $T_{\bar{d}}$, computed from the Argo profiles of Fig. 6a (North Pacific). (b) Upper Ocean Heat Content (OHC) and $T_{\overline{100}}$ for the North Pacific data (and note that this panel is below the corresponding panel (a)). In this deep, open ocean region, $T_{\overline{100}}$ and $T_{\bar{d}}$ are highly correlated with each other, and in the higher range of $\mathrm{OHC}$, they are both highly correlated with $\mathrm{OHC}$. In the low range of $\mathrm{OHC}$, where SST is close to $26^{\circ} \mathrm{C}$, the correlation between $\mathrm{OHC}$ and the depth-averaged temperatures is poor. $\mathrm{OHC}$ is zero on profiles where the temperature is less than $26^{\circ} \mathrm{C}$ throughout the water column, about one third of the profiles in this sample. (c) The vertically-averaged temperatures, $T_{\overline{100}}$ and $T_{\bar{d}}$, computed from the North Atlantic Argo profiles Fig. 6c. (d) OHC and $T \overline{100}$ from the North Atlantic data of (c). Same comments as apply for the North Pacific data.

continue on (though in light of P1 and P2 we might still ask why there is a correlation between high $\mathrm{OHC}$ and hurricane intensification). As discussed in Sect. 3.2, there may be shallow water regions that are equally favorable for hurricane intensification as assessed by a depth-averaged temperature, and yet that have comparatively low OHC. Cool, deep ocean regions are also relevant and interesting.

\subsubsection{Cooler oceans and the low range of $\mathrm{OHC}$}

OHC and $T_{\overline{100}}$ are not closely related in the range of low $\mathrm{OHC}, \mathrm{OHC} \leq 50 \mathrm{~kJ} \mathrm{~cm}^{-2}$ and low temperatures, $T \overline{100} \leq 26.5^{\circ} \mathrm{C}$ (Fig. $7 \mathrm{~b}$ and d). As noted in Sect. 1.1, neither is there a statistical correlation between hurricane intensity and $\mathrm{OHC}$ within this low range of $\mathrm{OHC}$ (Lin et al., 2008; Mainelli et al., 2008). This loss of correlation is somewhat puzzling because it has been observed that hurricanes are significantly damped by a sufficiently cool SST (Monaldo et al., 1997; Walker et al., 2005). On the face of it then, an ocean 
thermal metric would be expected to have a low range within which hurricane intensity is damped.

A partial resolution of this low OHC puzzle may be as close at hand as P1 and Eq. (3). And specifically, the loss of the tight relationship between high range $\mathrm{OHC}$ and the depth-averaged temperatures results in part from a slightly peculiar property built into $\mathrm{OHC}$, i.e., that all ocean temperatures less than the reference temperature $26^{\circ} \mathrm{C}$ are treated the same, effectively as zero. For example, if the temperature of the entire water column was $0^{\circ} \mathrm{C}$, then the estimated $\mathrm{OHC}$ would be zero, and if the temperature of the entire water column was $26^{\circ} \mathrm{C}$, then the $\mathrm{OHC}$ would again be exactly zero. Thus, insofar as $\mathrm{OHC}$ is concerned, $T=0$ and $T=26^{\circ} \mathrm{C}$ are one and the same. As a consequence, roughly a third of the open ocean temperature profiles considered here (Fig. 7) map into one point in $\mathrm{OHC}$-space, $\mathrm{OHC}=0$, which might be termed a cool degeneracy. In maps of $\mathrm{OHC}$, this cool degeneracy appears as broad regions that are at or near zero and so horizontally uniform. There is just a hint of this cool degeneracy along the northern boundary of the North Pacific OHC map computed in late September (Fig. 3) and it becomes quite prominent once seasonal cooling has developed in late October (see Goni and Trinanes (2003) and http: //www.aoml.noaa.gov/phod/cyclone/data/go.html for examples).

In Sect. 1 it was noted that the reference temperature of $\mathrm{OHC}, 26^{\circ} \mathrm{C}$, had a significant empirical basis. But whether there is a literal cutoff in hurricane-ocean interaction for $\mathrm{SST} \leq 26^{\circ} \mathrm{C}$ as occurs with $\mathrm{OHC}$ seems unlikely, if only because the dew point temperature of the hurricane lower atmosphere is typically a few ${ }^{\circ} \mathrm{C}$ less than the air temperature, and so some latent heat flux would be expected even for $\mathrm{SST} \leq 26^{\circ} \mathrm{C}$. What appears to be certain is that $\mathrm{OHC}$ defined by Eq. (3) will have poor (or no) resolution in regions where the upper ocean temperature is less than $26^{\circ} \mathrm{C}$ and hence $\mathrm{OHC}$ could not be expected to provide a nuanced account of the possible damping effect of still lower SST. This limitation of OHC is not shared by a depth-averaged temperature, which can always be referenced to 24 or $26^{\circ} \mathrm{C}$. For example, maps of $T_{\overline{100}}-26$ or $\left(T_{i}+T_{\overline{100}}\right) / 2-26$ (discussed in Sect. 4.3) would give a much more vivid impression of a warm or cool sea surface than does $T_{\overline{100}}$ alone.

\subsection{The coastal ocean}

$\mathrm{OHC}$ and the depth-averaged temperatures can be quite different when evaluated over shallow water regions. The consequence for forecasts of hurricane-ocean interaction may be more or less significant depending upon the extent of the shallow water area affected and the relationship of a hurricane track to the coastline (incidence angle). The shallow water limit is of interest in the present context because it clearly shows the difference between integrating and averaging. The shallow water limit is of considerable practical importance for hurricane forecasting since it occurs in conjunction with hurricane land fall.

To illustrate the effects of bottom depth, OHC and $T_{\bar{d}}$ were evaluated over an idealized continental shelf that was constructed along the lines of the West Florida Continental Shelf (Fig. 8a). The bottom slope was taken to be $\partial b / \partial x=10^{-3}$ and constant, with $b$ the bottom depth, and $x$ the acrossshelf coordinate. The hydrography of continental shelves varies a great deal from region to region and on a given shelf with time (Allen et al., 1983) with important consequences for what follows. But given that the goal here is to illustrate bottom depth effects alone, the thermocline was presumed to be level so that $T_{i}(x, y, z)=T_{i}(z)$ and horizontally homogeneous for $z \geq-b(x)$. i.e., upwelling neutral. The temperature profile $\bar{T}_{i}(z)$ was taken from the West Florida Shelf in summer (Hu and Muller-Karger, 2007) and had a warm and quasi-uniform surface layer about $25 \mathrm{~m}$ thick, and a comparatively large vertical gradient of temperature, $0.15^{\circ} \mathrm{C} \mathrm{m}^{-1}$, within the seasonal thermocline. This kind of shallow, strongly stable seasonal thermocline is typical of subtropical shelf regions that are not directly influenced by deep ocean currents, e.g., the South and Middle Atlantic Bights (Schofield et al., 2008), if not impacted by Gulf Stream-derived eddies, or the shelf regions along the northern Gulf of Mexico, aside from Loop Current eddies. The metrics $\mathrm{OHC}$ and $T_{\bar{d}}$ were then sampled along a transect across the shelf (Fig. 8b and c).

\subsubsection{Coastal ocean OHC}

To evaluate $\mathrm{OHC}$ over shallow waters in which the bottom temperature exceeds $26^{\circ} \mathrm{C}$, the lower limit of integration was presumed to be the bottom depth, $b$. Given this specific shelf and hydrography, the estimated $\mathrm{OHC}$ begins to decrease as the bottom depth becomes less than the depth of the $26^{\circ} \mathrm{C}$ isotherm, which is about $50 \mathrm{~m}$ in the temperature profile presumed here (Fig. 8b). Assuming a consistent deep-ocean and coastal-ocean interpretation of $\mathrm{OHC}$, i.e., that regions having $\mathrm{OHC} \leq 50 \mathrm{~kJ} \mathrm{~cm}^{-2}$ are not favorable for hurricane intensification (or at least less so than high $\mathrm{OHC}$ regions), then according to $\mathrm{OHC}$, a shallow continental shelf would appear to be an unfavorable environment for hurricane intensification.

This simple example of a coastal ocean shows that $\mathrm{OHC}$ can vanish in two important, realizable limits: 1) over the deep ocean as $T \rightarrow 26^{\circ} \mathrm{C}$ from above, and discussed in the previous section, and, 2) over a coastal ocean as $b \rightarrow 0$ and regardless of the ocean temperature. If the underlying issue for hurricane-ocean interaction is SST rather than OHC per se, as we have argued it must be in P1 and P2 of Sect. 2, then it appears that OHC suffers from a second kind of degeneracy in shallow water in that very low values of $\mathrm{OHC}$ will be estimated in shallow-enough water even if the ocean temperature is high. Said a little differently, low values of OHC in a coastal ocean are not expected to have the same consequence for hurricane-ocean interaction as do low values of 

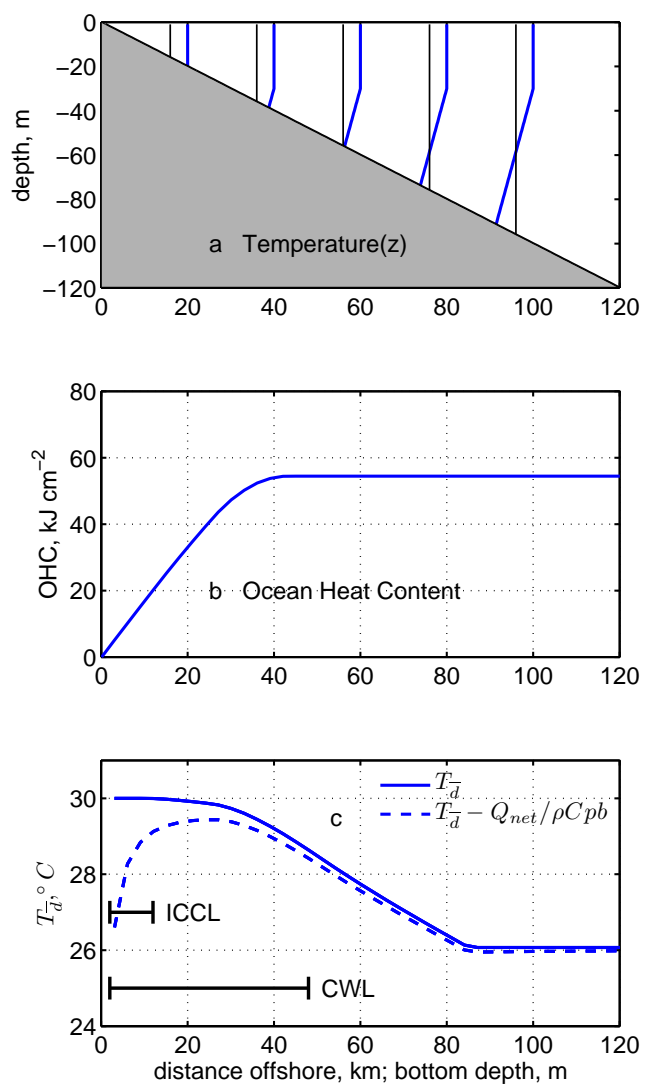

Fig. 8. The variation of $\mathrm{OHC}$ and $T_{\bar{d}}$ along a transect of an idealized continental shelf that could be characterized as fairly broad and upwelling neutral. (a) The temperature profile came from the West Florida Continental Shelf. The thin vertical lines are at $26^{\circ} \mathrm{C}$ and the scale for temperature is as for distance. The bottom slope is about 1.5 to 2 times that of the West Florida Shelf. (b) OHC decreases with decreasing bottom depth, $d \leq 40 \mathrm{~m}$, which is slightly less than the depth of the $26^{\circ} \mathrm{C}$ isotherm. (c) SST profiles across the shelf. The $\mathrm{SST}_{i}$ (not shown) was taken to be $30^{\circ} \mathrm{C}$ and uniform. $T_{\bar{d}}$ increases with decreasing bottom depth less than $85 \mathrm{~m}$, the depth of mixing estimated for this stratification over a deep ocean. The dashed line is $T_{\bar{d}}$ modified with a nominal heat loss to the hurricane. ICCL is the width of the Inner-Coastal Cool Layer (Sect. 3.3.2) and CWL is the width of the Coastal Warm Layer.

OHC over the deep ocean. The combined effect of this cool and shallow water degeneracy is thought to be a part of the reason that $\mathrm{OHC}$ does not show a correlation with hurricane intensification in the low range of $\mathrm{OHC}$.

\subsubsection{Coastal ocean $T_{\bar{d}}$}

A coastal warm layer. Given the shelf topography and stratification presumed here, the depth-averaged temperature $T_{\bar{d}}$ increases as the bottom depth becomes less than $d_{d o}=85 \mathrm{~m}$, the depth of mixing over the deep ocean given this rather stable stratification. The increase of $T_{\bar{d}}$ shoreward of the $85 \mathrm{~m}$ isobath (Fig. 8c) follows from the increase of bottom temperature with decreasing bottom depth, i.e., there is less cold water available to be mixed upwards. This can be expected over a shelf on which the seasonal thermocline intersects the bottom, i.e., over shelves that are either upwelling neutral or negative, but not on shelves that are upwelling positive. The end result for an upwelling neutral shelf is that the acrossshelf temperature profile $T(x)$ exhibits what might be termed a Coastal Warm boundary Layer (CWL), whose half-width may be estimated roughly as

$W_{C W L} \approx \frac{1}{2} d_{d o} / \frac{\partial b}{\partial x}$,

and in this case, $W_{C W L}=42 \mathrm{~km}$.

An inner-coastal cool layer. Heat loss to the hurricane must become a significant process for sea surface cooling where the water is shallow enough (Shen and Ginis, 2003). To account approximately for this hurricane-ocean heat exchange, the depth-averaged temperature $T_{\bar{d}}$ can be perturbed by subtracting a typical net hurricane-ocean heat flux, $Q_{\text {net }}$, from the water column. $Q_{\text {net }}$ is estimated from the numerical simulation of the Frances (2004) case by Sanford et al. (2007) by integrating the latent and sensible heat fluxes over a period of one day centered on the hurricane passage, $Q_{\text {net }} \approx 5 \times 10^{7} \mathrm{~J} \mathrm{~m}^{-2}$, or in the non-SI units often used for OHC, $Q_{\text {net }} \approx 5 \mathrm{~kJ} \mathrm{~cm}^{-2}$. This estimate appears to be at least roughly consistent with the heat fluxes estimated by Chen et al. (2007) for the Frances (2004) case, and by Cione and Uhlhorn (2003) for other hurricanes. The revised depthaveraged temperature that takes account of this heat loss, $T_{\bar{d}}-Q_{\text {net }} / \rho_{o} C_{p} b$, where $b$ is the water depth, is shown as the dashed line of Fig. 8c. The resulting Inner-Coastal Cool boundary Layer (ICCL), follows the qualitative expectations of $\mathrm{OHC}$ in the sense that the cooling is inversely related to water depth, $b$. The width of this cool layer may be estimated roughly as the region where the temperature is decreased by say $\Delta T=1^{\circ} \mathrm{C}$ or more,

$W_{\mathrm{ICCL}} \approx \frac{Q_{\mathrm{net}}}{\rho_{o} C_{p} \Delta T} / \frac{\partial b}{\partial x}$,

and in this case, $W_{\mathrm{ICCL}}=12 \mathrm{~km}$.

Thus the post-hurricane coastal ocean sea surface temperature computed by the $T_{\bar{d}}$ model may show two boundary layers when compared to the outlying and otherwise similar deep ocean - a coastal warm layer (CWL, and warm compared to the outlying deep ocean) in which the characteristic process is a reduced heat flux associated with vertical mixing, and an inner-coastal cool layer (cool compared to the warm layer), in which hurricane ocean heat exchange is important. This ICCL follows the expectations implicit to OHC, and a comparison of the amplitude and width of the ICCL and the CWL gives a visual impression of the relative importance of vertical mixing and hurricane-ocean heat exchange, insofar as the SST over a continental shelf is concerned. Given the upwelling neutral shelf considered here, the outer warm layer 
is considerably wider than the inner cool layer. For typical bottom slopes and heat loss values,

$\frac{W_{\mathrm{CWL}}}{W_{\mathrm{ICCL}}}=\frac{d_{d o} / 2}{Q_{\text {net }} / \rho_{o} C_{p} \Delta T} \approx 3.5$

\subsubsection{Applications and coastal ocean observations}

The maps of Figs. 3 and 4 show $T_{\overline{100}}$ and $\mathrm{OHC}$ evaluated over the broad, shallow continental shelf off of the south and east coast of China (South China Sea north to the Yellow Sea). These are depicted as regions of generally low OHC, $\leq 40 \mathrm{~kJ} \mathrm{~cm}^{-2}$, despite having fairly high SST, simply because they are shallow. In contrast, the estimated depth-averaged temperature (Fig. 4 is $T_{\overline{100}}$ which has the same relation to bottom depth as does $T_{\bar{d}}$ ) indicates that these shelf regions are likely to remain fairly warm during a hurricane passage by virtue of the CWL phenomenon. Hence on our P3 (Sect. 2.1) these shelf regions appear to be somewhat favorable for hurricane intensification, as seen in a depth-averaged temperature $T_{100} \geq 27^{\circ} \mathrm{C}$. Some of the effected shelf regions are as wide as several hundred kilometers and likely to be of significance for hurricane-ocean interaction, or at least for our prediction of hurricane-ocean interaction. Other shelf regions appear nearly the same when diagnosed with $\mathrm{OHC}$ or $T_{\overline{100}}$, notably east of the Phillipines, where the continental shelf is quite narrow. To summarize, the distribution of $T_{\overline{100}}$ indicates that some coastal oceans - those having broad, shallow continental shelves and hydrography that is upwelling neutral or negative - are expected to remain warm during a hurricane passage, and in that regard would appear to be favorable environments for hurricane intensification. This is a result at odds with a consistent deep-ocean/shallow-water interpretation of $\mathrm{OHC}$.

As hurricanes cross a continental shelf they are also likely to be making land fall, which is usually expected to cause a rapid and significant decrease of hurricane intensity (but see McTaggart-Cowen et al. (2007) who note that this is not necessarily the case if the land surface is flat, warm and wet, e.g., South Florida). However, our concern here is exclusively with the ocean thermal field, and some evidence is that shallow water environments may indeed be favorable for hurricane intensification in the sense that hurricane-induced sea surface cooling has been observed to be reduced over shallow water regions compared to the cooling over outlying, deep water regions. Hazelworth (1968) analyzed the time series data from weather ships for hurricane passages and made a very brief and tentative mention of such a shallow water effect. The first explicit report was evidently made by Cornillon et al. (1987), and more recently this phenomenon has been observed on the West Florida Continental Shelf by $\mathrm{Hu}$ and Muller-Karger (2003). The latter two studies inferred that the principal cause of the reduced sea surface cooling over shallow water was the absence of cool water at depths that could be mixed into the surface layer, just as happens here with the depth-averaged temperature. Emanuel (1999) noted the relevance of this shallow water effect in the context of hurricane-ocean interaction. ${ }^{2}$

\subsection{Salt-stratified water column}

In the event that salinity makes an important contribution to the upper ocean density stratification, then $T_{\bar{d}}$ can, in principle, differ from both $\mathrm{OHC}$ and $T_{\overline{100}}$ which acknowledge temperature only. Important salinity effects may arise where there is a comparatively fresh ocean surface layer, which often occurs in a coastal ocean, and especially down-coast from the estuary of a major river (Bingham, 2007). There are also open ocean regions in which salinity makes an appreciable contribution to the static stability of the upper ocean, e.g., the barrier layer of the western tropical Pacific and parts of the northern Indian Ocean (McPhaden et al., 2009).

If the net salinity anomaly (thickness times salinity anomaly in the initial state) is as large as about $20 \mathrm{~m}$, then the fresh layer will inhibit vertical mixing significantly. The effect upon the sea surface temperature will depend upon whether the fresh layer is warmer or cooler than the water below. If the former, then salinity stratification will act to reduce the depth of vertical mixing and thus sea surface cooling. If the latter, then vertical mixing will act to increase the surface temperature (see the Nordic Sea example of Saetra et al., 2003), a possibility missing altogether from $\mathrm{OHC}$, which omits any reference to salinity (or density). This anomalous surface warming effect of vertical mixing is present in $T_{\overline{100}}$ when the temperature profile has an inversion, but in general, a salinity effect upon static stability requires an explicit treatment of density, e.g., by means of $T_{\bar{d}}$ or something more comprehensive.

\section{Closing remarks}

\subsection{Summary}

The standard metric of the ocean thermal field within hurricane-ocean interaction is a depth-integrated ocean temperature, upper Ocean Heat Content or OHC. OHC has been shown to provide valuable forecast guidance in warm, deep ocean conditions for which it was first formulated (Leipper

\footnotetext{
${ }^{2}$ During the summer of 2005 there were a number of intense hurricanes that crossed over the Gulf of Mexico, including Katrina (2005), which passed over the Louisiana shelf, and Wilma (2005), which passed over Florida Bay and the southern end of the West Florida shelf. SST imagery of these significant events provides some additional qualitative evidence of a coastal warm layer and sometimes a hint of an inner-coastal cool layer, though not distinct from land effects; see the collection of GOES-12 SST images in the Supplementary Material noted at the end. A comprehensive resource is the Louisiana State University Earth Scan web site, http://www.esl.lsu.edu/quicklinks/hurricanes/. Almost needless to say, attributing the cause of SST change, given only satellite images, is very uncertain.
} 
and Volgenau, 1972; Lin et al., 2008; Mainelli et al., 2008) but the argument made here is that a depth-averaged temperature, $T_{\overline{100}}$ or $T_{\bar{d}}$, may be more appropriate over a much wider range of conditions. The argument was made on three premises: P1, that SST and especially SST under a hurricane is the directly relevant ocean variable; $\mathrm{P} 2$ an ocean region is favorable for hurricane intensification if SST remains high during a hurricane passage; and $\mathrm{P} 3$, the observation that cooling is due mainly to vertical mixing rather than to hurricane-ocean heat exchange. The hypotheses of this paper follows: H1 a depth-averaged ocean temperature is the appropriate metric (or proxy) for SST under a hurricane, and the corollary is that a depth-averaged temperature is a more robust metric of hurricane-ocean interaction than is OHC.

The majority of hurricanes and typhoons form over the deep, open ocean in late summer when sea surface temperature is warmest. In that most important circumstance, $\mathrm{OHC}$ and $T_{\overline{100}}$ or $T_{\bar{d}}$ will provide essentially the same forecast guidance, i.e., that an ocean region having a warm $\left(T \geq 26^{\circ} \mathrm{C}\right)$ and especially thick surface layer will be a favorable environment for hurricane intensification. This has been observed to hold in forecasting practice (Sect. 1.2). This observation could be taken as a warrant for the original rationale for $\mathrm{OHC}$ - that a high $\mathrm{OHC}$ region resists cooling due to hurricaneocean heat exchange. This is true, of course, but we have argued in Sect. 2.1 that it is not highly germane. Equally, this observation could be taken as evidence in favor of $T_{\overline{100}}$ or $T_{\bar{d}}$ - that a thick, warm surface layer resists the cooling effect of vertical mixing. This latter interpretation is espoused in most recent studies (Lin et al., 2008; McTaggart-Cowen et al., 2007; Mainelli et al., 2008) and is the interpretation that is consistent with a depth-averaged temperature metric. If only warm and deep ocean conditions were relevant to hurricane-ocean interaction, then this inference of mechanisms would be of academic interest, but would hold little practical importance (Fig. 9). ${ }^{3}$

\footnotetext{
${ }^{3}$ The seasonal cycle of cooling on warm subtropical continental shelves serves as an interesting counterpoint to the hurricaneocean interaction phenomenon of interest here. Around the Gulf of Mexico, the cooling phase of the seasonal cycle begins in earnest with the first cold air outbreak (see the satellite imagery noted above and the cold air outbreak beginning in mid-October, 2005 following the passage of Hurricane Wilma, 2005). Where a hurricane can be characterized by very strong winds and a rather small air-sea temperature difference, cold air outbreaks over the Gulf of Mexico are the complement in the sense that they have moderate wind speeds but very cold and dry air that sets up a very large air-sea temperature difference that is sustained for several days. Hence, while a cold air outbreak must cause some vertical mixing (Lentz et al., 2003), it will certainly also cause very significant heat loss from the ocean. The spatial pattern of the sea surface cooling following a cold air outbreak follows the qualitative expectations of $\mathrm{OHC}$ : shallow, inner shelf regions (small $\mathrm{OHC}$ ) clearly cool in advance of deeper, outer shelf regions (larger $\mathrm{OHC}$ ). The cooling phase of the seasonal cycle on subtropical continental shelves might thus be
}

However, there are three other fairly common circumstances in which the inference of mechanism is crucially important in as much as $\mathrm{OHC}$ and depth-averaged temperature will give quite different forecast guidance.

Cool, open ocean waters. Hurricanes form over warm (SST $\geq 26^{\circ} \mathrm{C}$ ) ocean regions, but may later move over much lower SSTs during their lifetime (a striking example is shown by Monaldo et al., 1997). The cool degeneracy built in to OHC effectively restricts its application to warm ocean conditions. The depth-averaged temperatures do not have this property, and an analysis of $T_{\overline{100}}$ or $T_{\bar{d}}$ could, in principle, permit the forecast of a damping effect of cool sea surface temperatures upon hurricane intensity.

Salt-stratified waters. While temperature is a sufficient proxy for density and static stability in most conditions, salinity can have a significant and sometimes decisive effect on static stability in special locations, for example within or near estuaries. $\mathrm{OHC}$ and $T_{\overline{100}}$ are silent on salinity effects, which can be accounted by the $T_{\bar{d}}$ metric provided that the initial salinity is known.

Shallow waters. $\mathrm{OHC}$ and the depth-averaged temperatures can be quite different when evaluated over shallow, continental shelf regions. OHC will generally indicate that shallow regions (shallow compared to the depth of the $26^{\circ} \mathrm{C}$ isotherm) are an unfavorable environment for hurricane intensification, while $T_{\overline{100}}$ or $T_{\bar{d}}$ may indicate the opposite, that shallow regions (shallow compared to the depth of vertical mixing in the deep ocean) can be favorable for hurricane intensification compared to an otherwise similar deep ocean (Fig. 9). To the point - this study indicates that, land effects aside, a shallow, warm continental shelf may be as favorable for hurricane intensification as is a deep, open ocean, warm regime, e.g., the Loop Current or warm eddies of the subtropical gyre interior (compare the depth averaged-profiles of Fig. 5a and c).

\subsection{Remarks on the coastal ocean}

The variation of SST with distance offshore is at once the most readily observed property of the coastal ocean and is the property of immediate interest for hurricane-ocean interaction and forecasting. It is important to appreciate that the specific relationship between SST and distance offshore shown in Fig. 8c is by no means universal because the hydrography of any given continental shelf may be quite different from the upwelling neutral case considered in Sect. 3.2. The thermal field on most continental shelves depends upon the depth and (at least) the cross-shelf coordinate, $x$, so that $T=T(x, z)$. In shelf regions that are upwelling positive, e.g., Campeche Bank or the Louisiana-Texas shelf in late summer

seen as a macro version of the inner-coastal cool layer described in Sect. 3.2.2. In other words, something akin to $\mathrm{OHC}$ is the relevant metric for the SST response when air-sea heat exchange is the dominant physical process, i.e., the seasonal cooling of subtropical shelves but not the upper ocean response to a hurricane. 

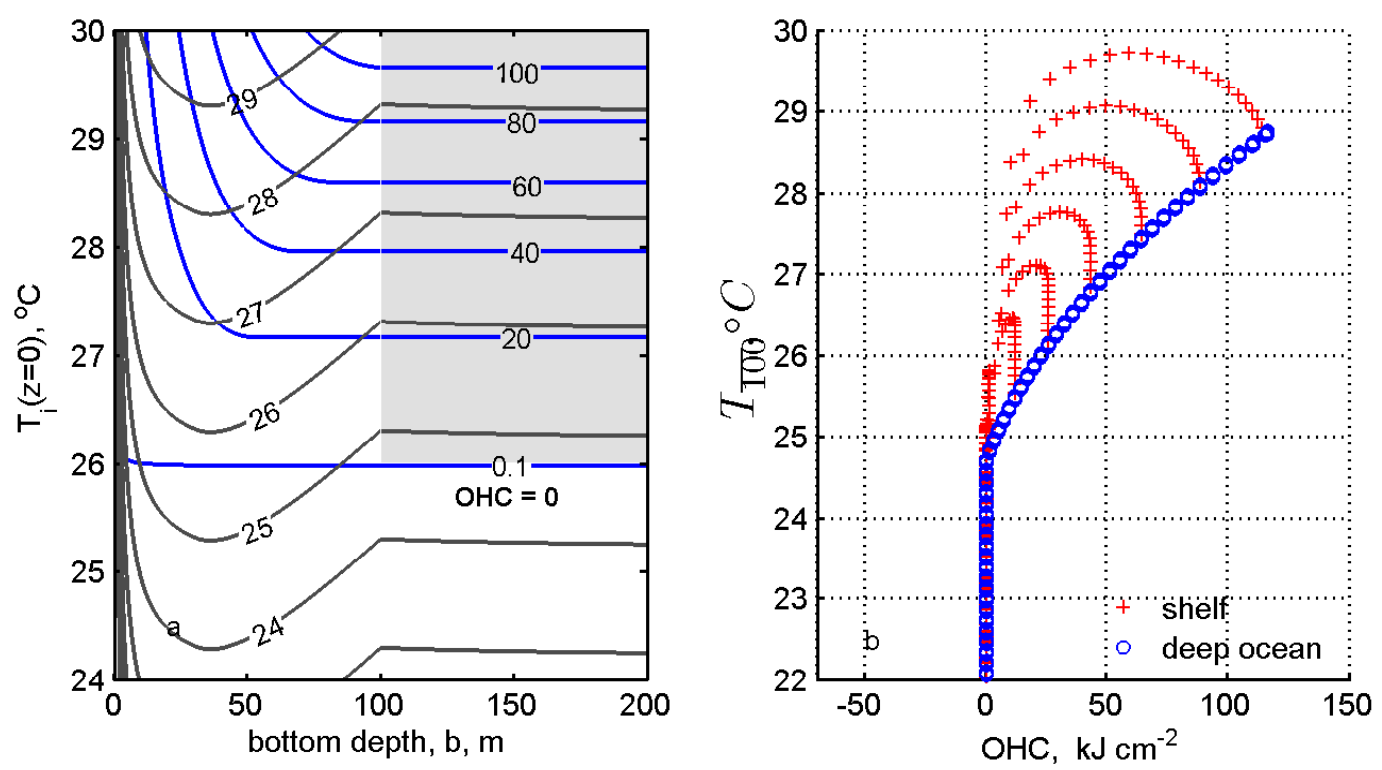

Fig. 9. (a) Dependence of $\mathrm{OHC}$ (thin dark blue lines) and $T \overline{100}$ (thicker gray lines) upon initial ocean temperature and bottom depth. The bottom slope was as in Fig. 8a. The temperature profile had a $30 \mathrm{~m}$ thick mixed layer and a constant vertical gradient, $0.05^{\circ} \mathrm{C} \mathrm{m}{ }^{-1}$, typical of the open ocean. The temperature was varied by subtracting a constant, 0 to $6^{\circ} \mathrm{C}$, from the entire profile. Both $\mathrm{OHC}$ and $T \overline{100}$ increase with increasing ocean temperature. Over the deep ocean and for warm temperatures, $\mathrm{OHC}$ and $T_{\overline{100}}$ are similar (the lightly shaded, upper right quadrant). However, the dependence upon bottom depth is quite different and reflects the difference between vertically-integrating, OHC, which has a maximum at the warmest temperature and the greatest bottom depth, or vertically-averaging, $T \overline{100}$, which has a maximum at the warmest temperature and a bottom depth of $30 \mathrm{~m}$, the initial mixed layer thickness. (b) A scatter diagram of the data at left. The big blue dots are from the deep ocean, and the fan of red points are from the continental shelf (the spacing of these points is arbitrary). Notice that for this temperature profile (constant vertical gradient) $\mathrm{OHC}$ and $T \overline{100}$ are exactly similar for warm temperatures over the deep ocean (cf. Fig. $7 \mathrm{~b}$ and $\mathrm{d}$ where this is not the case). $\mathrm{OHC}$ and $T \overline{100}$ are decidedly not similar over the continental shelf.

(Walker, 2005; see also the SST imagery of the Supplementary Material), the thermocline will be lifted toward the coast $\left(\frac{\partial T}{\partial x} \geq 0\right.$ for the configuration of Fig. 8a) so that cool water may be present very close to shore and very close to the sea surface. Over such an upwelling positive shelf region there may be greater SST cooling than over the outlying, deep ocean, i.e., the reverse of the CWL phenomenon. On some shelves, e.g., the Middle Atlantic Bight, the early summer thermocline may be thin enough, $\mathrm{O}(30 \mathrm{~m})$ (Schofield et al., 2008) that the width of the coastal warm layer may be no more than a few kilometers, and negligible. Given the great range and temporal variability of coastal ocean hydrography, a key requirement for forecasting hurricane-ocean interaction over shelf regions will be to observe and to model the ocean stratification in more or less real time.

The present treatment of the coastal ocean response to a hurricane (Sect. 3.2.2) was simplified to the point that $T_{\bar{d}}$ could be characterized as a null model: the estimated (deep ocean) vertical mixing was simply stopped if it reached the ocean bottom. That must happen, of course, but so may a great deal else that was outside the scope of this greatly simplified treatment. For example, rotary inertial motions, the dominate mode of open ocean, wind-driven currents, must be inhibited near coast lines. At a minimum, there must occur transient up- and down-welling that was not accounted for in the local version of $T_{\bar{d}}$ presented here. Surface gravity waves generated by an approaching hurricane can be very energetic, and may cause intense vertical mixing within a thick bottom boundary layer, even before the direct effect of the hurricane wind stress reaches the bottom (Glenn et al., 2008). Finally, the pre-hurricane thermal and salinity fields around continental shelves will often vary in three dimensions, with marked effects on the post-hurricane SST and salinity observed at fixed sites (Xie et al., 1997; Chu et al., 2000 and Bingham, 2007). When the possibilities of variable hurricane incidence angle and translation speeds are considered in combination with one or more of the coastal phenomenon noted above, then it becomes evident that the parameter space for hurricane-coastal ocean interaction is very extensive and well worth additional study and synthesis (Manzello et al., 2007). We certainly need to understand which map - OHC in Fig. 3 or $T_{100}$ in Fig. 4 - gives the better forecast guidance over continental shelves, and over cool, open ocean regions. 


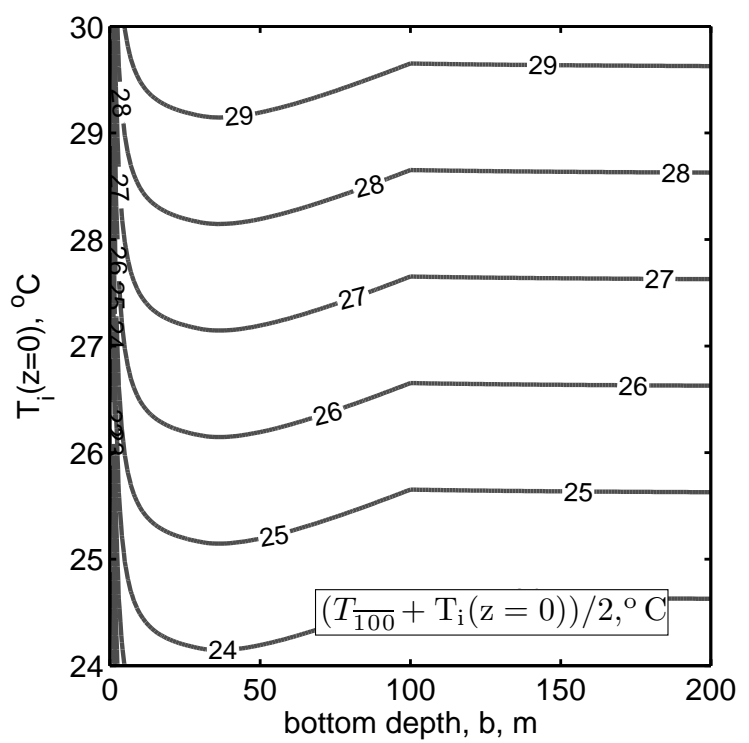

Fig. 10. The simple average of $T \overline{100}$ and the initial SST for the data of Fig. 9a. This temperature is thought to be a better estimator of the SST under the high wind speed, central region of a hurricane than is $T_{\overline{100}}$, and in that regard may be the most relevant SST insofar as hurricane-ocean interaction is concerned. It is, of course, also much harder to observe. Notice that this temperature is slightly greater than $T_{\overline{100}}$ over the deep ocean, $z>-b$ (cf. Fig 9a) and nearly equal to $T_{i}$ over the mid-continental shelf.

\subsection{A look ahead}

Forecasting of hurricanes or any natural phenomenon is a pragmatic endeavor. Insight from models and observations can help point the way to new hypotheses or methods, but forecasting success can only be told from actual practice (Lin et al., 2008; Mainelli et al., 2008) which was beyond the scope of this paper. The best result of this discussion would be to stimulate a fresh look at hurricane-ocean interaction, and specifically, to encourage further testing of ocean metrics drawn from an expanded hypothesis-space. Just two examples:

A revised OHC. The conservation error of $\mathrm{OHC}$ (footnote 1 of Sect. 1)and the cool degeneracy noted in Sect. 3.1.2 could be remedied for most hurricane analysis or forecasting purposes simply by choosing a reference temperature that is below the depth of vertical mixing and the lower limit of relevant SSTs, e.g., $22^{\circ} \mathrm{C}$. This variant of $\mathrm{OHC}$ will have improved conservation and statistical properties over a wider range of conditions than does the usual form, Eq. (3), but there is still no guarantee that heat content will be the most relevant physical quantity for hurricane-ocean interaction over shallow continental shelves (Sect. 3.2) and especially those that are to some degree salt-stratified (Sect. 3.3).

A derivative of $T_{\overline{\mathbf{d}}}$. The depth-averaged temperatures estimated here were intended to be the minimum of SST expected in a hurricane wake, i.e., displaced behind the strongest winds of a moving hurricane. The SST cooling directly under a hurricane can be considerably less than the maximum cooling seen in the wake (Cione and Uhlhorn, 2003; D'Asaro et al., 2007, and see also Wu et al., 2005), and it seems likely that hurricane-ocean interaction would be better represented by, e.g., a weighted average of the observed, initial SST and $T_{\bar{d}}$ (a simple average is in Fig. 10). In a similar way, if the issue on a given day was the possible intensification of a moderate tropical storm, then a much reduced wind stress amplitude in the mixing depth model (Eq. 5), $\tau=1 \mathrm{~Pa}$, would be appropriate. Treatment of very slowly moving or quasi-stationary storms would benefit from an explicit treatment of upwelling (see the remarks in the Supplementary Material) and, in shallow water, heat loss to the hurricane.

Identifying the optimum ocean metric is an important and significant challenge; $\mathrm{OHC}$ and depth-averaged temperatures are well-correlated in some important circumstances and, in any event, the ocean thermal field is just one of several factors that make up the complex environment of a hurricane. A thorough exploration and sensitive test of ocean metrics will require a large suite of case studies that span the full range of ocean conditions that are relevant for hurricane-ocean interaction. No doubt such a study could be aided considerably by guidance from the best possible air and sea coupled models that include a coastal ocean.

\section{Supplementary Material}

Supplementary material includes:

1. A Matlab script that evaluates an arbitrary density profile for the depth of mixing and the depth-averaged temperature, $T_{d}$.

2. A description of a comparison of $T_{d}$ with solutions of the 3D-PWP numerical ocean model.

3. A collection of GOES SST imagery of the Gulf of Mexico during the summer of 2005.

Available online:

http://www.ocean-sci.net/5/351/2009/

os-5-351-2009-supplement.zip

Acknowledgements. This research was supported by the US Office of Naval Research through the project Impact of Typhoons on the Western North Pacific (ITOP). Thanks to Tom Sanford of the Applied Physics Laboratory, University of Washington for the EM-APEX data of Fig. 1 and for valuable comments on a draft manuscript. Thanks to J. J. Park and Young-Oh Kwon of the Woods Hole Oceanographic Institution for the quality-controlled Argo data sets and to ITOP colleagues Dong-Shan Ko of the Naval Research Laboratory, Steve Jayne of the Woods Hole Oceanographic Institution, Eric D'Asaro of the Applied Physics Laboratory, University of Washington, I-I Lin and Iam-Fei Pun of Taiwan National University, Shuyi Chen of the University of Miami and Peter Black of 
Science Applications International for valuable discussions of this research. Tom Farrar, Kristen Davis and Bruce Warren of Woods Hole Oceanographic Institution provided insightful comments on a draft manuscript and Nan Walker of Louisiana State University, Ruoying He of North Carolina State University and Ken Brink of the Woods Hole Oceanographic Institution are thanked for their advice on the coastal ocean. The satellite images of Fig. 1 are from the JPL POET data server, and the NOAA/NESDIS Environmental Visualization Program.

Edited by: M. Hecht

\section{References}

Allen, J. S., Beardsley, R. C., Blanton, J. C., et al.: Physical oceanography of continental shelves, Rev. Geophys. Space Phys., 21(5), 1149-1181, 1983.

Bender, M. A., Ginis, I., and Kurihara, Y.: Numerical simulations of tropical cyclone-ocean interaction with a high resolution coupled model, J. Geophys. Res., 98, 23245-23263, 1993.

Bender, M., Ginis, I., Tuleya, R., Thomas, B., and Marchok, T.: The operational GFDL coupled hurricane-ocean prediction system and a summary of its performance, Mon. Wea. Rev., 135, 3965-3989, 2007.

Bingham, F. M.: Physical response of the coastal ocean to Hurricane Isabel near landfall, Ocean Sci., 3, 159-171, 2007, http://www.ocean-sci.net/3/159/2007/.

Black, P. G., D’Asaro, E., Drennan, W., French, J. R., Sanford, T. B., Terrill, E. J., Niiler, P. P., Walsh, E. J., and Zhang, J.: Air-sea exchange in hurricanes: Synthesis of observations from the Coupled Boundary Layer Air-Sea Transfer Experiment, Bull. Amer. Met. Soc., 88, 357-374, 2007.

Chen, S. S., Price, J. F., Zhao, W., Donelan, M. A., and Walsh E. J.: The CBLAST-Hurricane program and the next-generation fully coupled atmosphere-wave-ocean models for hurricane research and prediction, Bull. Amer. Met. Soc., 88, 311-317, 2007.

Chu, P. C., Veneziano, J. M., Fan, C., Carron, M. J., and Liu,W. T.: Response of the South China Sea to Tropical Cyclone Ernie 1996, J. Geophys. Res., 105(C6), 13991-14009, 2000.

Cione, J. J. and Uhlhorn, E. W.: Sea surface temperature variability in hurricanes: Implications with respect to intensity change, Mon. Wea. Rev., 131, 1783-1796, 2003.

Cornillon, P., Stramma, L., and Price, J. F.: Satellite observations of sea surface cooling during hurricane Gloria, Nature, 326, 373375, 1987.

D’Asaro, E. A., Sanford, T. B., Niiler, P. P., and Terrill, E. J.: Cold wake of Hurricane Frances, Geophys. Res. Lett., 34, L15609, doi:10.1029/2007GRL030160, 2007.

DeMaria, M., Mainelli, M., Shay, L. K., Knapf, J. A., and Kaplan, J.: Further improvements to the Statistical Hurricane Intensity Prediction Scheme (SHIPS), Wea. Forecast., 20, 531-543, 2005.

Emanuel, K. A.: Thermodynamic control of hurricane intensity, Nature, 401, 665-669, 1999.

Ginis I.: Tropical cyclone-ocean interactions, in: AtmosphereOcean Interactions, edited by: Perrie, W., WIT Press, Advances in Fluid Mechanics Series, 33, 83-114, 2002.

Glenn, S., Jones, C., Twardowski, M., Bowers, L., Kerfoot, J., Kohut, J., Webb, D., and Schofield, O.: Glider observations of sediment resuspension in a Middle Atlantic Bight fall transition storm, Limnol. Oceanogr., 53(5, part 2), 2180-2196, 2008.

Goni, G. J. and Trinanes, J. A.: Ocean thermal structure monitoring could aid in the intensity forecast of tropical cyclones, Eos. Trans. Amer. Geophys. Union, 84, 573-580, 2003.

Halliwell, G. R., Shay, L. K., Jacob, S. D., Smedstad, O. M., and Uhlhorn, E. W.: Improving ocean model initialization for coupled tropical cyclone forecast models using GODAE nowcasts, Mon. Wea. Rev., 136, 2576-2591, 2008.

Hazelworth, J. B.: Water temperature variation resulting from hurricanes, J. Geophys. Res., 73(16), 5105-5123, 1968.

$\mathrm{Hu}, \mathrm{C}$. and Muller-Karger, F. E.: Response of sea surface properties to Hurricane Dennis in the eastern Gulf of Mexico, Geophys. Res. Lett., 34, L07606, doi:10.1029/2006GRL028935, 2007.

Jacob, S. D., Shay, L. K., Mariano, A. J., and Black, P. G.: The 3d oceanic mixed layer response to hurricane Gilbert, J. Phys. Oceanogr., 30, 1407-1429, 2000.

Ko, D. S., Martin, P. J., Rowley, C. D., and Preller, R. H.: A realtime coastal ocean prediction experiment for MREA04, J. Mar. Sys., 69, 17-28, doi:10.1016/j.jmarsys.2007.02.022, 2008.

Leipper, D. and Volgenau, D.: Upper ocean heat content of the Gulf of Mexico, J. Phys. Oceanogr., 2, 218-224, 1972.

Lentz, S., Shearman, K., Anderson, S., Plueddemann, A., and Edson, J.: Evolution of stratification over the New England shelf during the Coastal Mixing and Optics study, August 1996-June 1997, J. Geophys-Res. Oceans, 108(C11), 8006, doi:10.1029/2001JC001121, 2003.

Lin, I.-I., Wu, C.-C., Pun, I.-F., and Ko, D.-S.: Upper ocean thermal structure and the western North Pacific category 5 typhoons, Part I: Ocean features and the category 5 typhoon's intensification, Mon. Wea. Rev., 136, 3288-3306, doi:10.1175/2008MWR2277.1, 2008.

Mainelli, M., DeMaria, M., Shay, L. K., and Goni, G.: Application of oceanic heat content estimation to operational forecasting of recent Atlantic category 5 hurricanes, Wea. Forecast., 23(1), 316, 2008.

Manzello, D. P., Brandt, M., Smith, T. B., Lirman, D., Hendee, J. C., and Nemeth, R. S.: Hurricanes benefit bleached corals, Proc. Nat. Acad. Sci., 104(29), 12035-12039, doi:10.1073/pnas.0701194104.

Marks, F. M., Shay, L. K., Barnes, G., et al.: Landfalling tropical cyclones: Forecast problems and associated research opportunities, Bull. Amer. Met. Soc., 79, 305-323, 1998.

McDougall, T. J.: Potential enthalpy: A conservative oceanic variable for evaluating heat content and heat fluxes, J. Phys. Oceanogr., 33, 945-963, 2003.

McPhaden, M. J., Foltz, G. R., Lee, T., Murthy, V. S. N., Ravichandran, M., Vecchi, G. A., Vialard, J., Wiggert, J. D., and Yu, L.: Ocean-atmosphere interactions during Cyclone Nargis, EOS Trans. AGU, 90, 53-60, 2009.

McTaggart-Cowan, R., Bosart, L. F., Gyakum, J. R., and Atallah, E. H.: Hurricane Katrina (2005), Part I: Complex life cycle of an intense tropical cyclone, Mon. Wea. Rev, 135, 3905-3926, 2007.

Monaldo, F. M., Sikora, T. D., Babin, S. M., and Sterner, R. E.: Satellite imagery of sea surface temperature cooling in the wake of Hurricane Edouard (1996), Mon. Wea. Rev., 125, 2716-2721, 1997.

Miller, B. I.: On the maximum intensity of hurricanes, J. Met., 15, 184-196, 1958. 
Price, J. F.: Upper ocean response to a hurricane, J. Phys. Oceanogr., 11, 153-175, 1981.

Price, J. F., Sanford, T. B., and Forristall, G. Z.: Forced stage response to a moving hurricane, J. Phys. Oceanogr., 24(2), 233260, 1994.

Qiu, B.: Seasonal eddy field modulation of the North Pacific Subtropical Countercurrent: TOPEX/Poseidon observations and theory, J. Phys. Oceanogr., 29, 1670-1685, 1999.

Saetra, O., Linders, T., and Debernard, J. B.: Can polar lows lead to a warming of the ocean surface?, Tellus A, 60, 141-153, 2008.

Sanford, T. B., Price, J. F., Girton, J. B., and Webb, D. C.: Highly resolved ocean response to a hurricane, Geophys. Res. Lett., 34, L13604, doi:10.1029/2007GL029679, 2007.

Schade, L. R. and Emanuel, K. A.: The ocean's effect on the intensity of tropical cyclones: results from a simple coupled atmosphere-ocean model, J. Atmos. Sci., 56, 642-651, 1999.

Scharroo, R., Smith, W. H. F., and Lillibridge, J. L.: Satellite altimetry and the intensification of Hurricane Katrina, EOS Trans. AGU, 86(40), p. 366, 2006.

Schofield, O., Chant, R., Cahill, B., Castelao, R., Gong, D., Kahl, A., Kohut, J., Montes-Hugo, M., Ramadurai, R., Ramey, P., Yi, X., and Glenn, S.: The decadal view of the Mid-Atlantic Bight from the COOLroom: Is our coastal system changing?, Oceanography, 21(4), 108-117, 2008.

Shay, L., Goni, G., and Black, P.: Effects of warm oceanic features on Hurricane Opal, Mon. Wea. Rev., 128, 131-148, 2000.

Shen, W. and Ginis, I.: Effects of surface heat flux-induced sea surface temperature changes on tropical cyclone intensity, Geophys. Res. Lett., 30(18), 1933, doi:10.1029/2003GRL017878, 2003.

Sriver, R. L. and Huber, M.: Observational evidence for an ocean heat pump induced by tropical cyclones, Nature, 447, 577-580, doi:10.1038/nature05785, 2007.

Sun, D., Gautam, R., Cervone, G., Boybei, Z., and Kafatos, M.: Comment on Satellite altimetry and the intensification of Hurricane Katrina, EOS Trans. AGU, 87(8), p. 89, 2006.
Tonkin, H., Holland, G. J., Holbrook, N., and Henderson-Sellers, A.: An evaluation of thermodynamic estimates of climatological maximum potential tropical cyclone intensity, Mon. Wea. Rev., 128, 746-762, 2000.

Walker, N. D.: Wind and eddy-related shelf/slope circulation processes and coastal upwelling in the northwestern Gulf of Mexico, in: Circulation in the Gulf of Mexico: observations and models, Geophys. Mon. Ser., 161, AGU, 295-314, 2005.

Walker, N. D., Leben, R. R., and Balasubramanain, S.: Hurricaneforced upwelling and chlorophyll $\alpha$ enhancement within coldcore cyclones in the Gulf of Mexico, Geophys. Res. Lett., 32, L18610, doi:10.1029/2005GL0023716, 2005.

Warren, B. A.: The first law of thermodynamics in a salty ocean, Progr. Oceanogr., 70, 149-167, 2006.

Willis, J. A., Roemmich, D., and Cornuelle, B.: Interannual variability in upper ocean heat content, temperature, and thermosteric expansion on global scales, J. Geophys. Res., 109, C12036, doi:10.1029/2003JC002260, 2004.

Wu, L. , Wang, B., and Braun, S. A.: Impacts of air-sea interaction on tropical cyclone track and intensity, Mon. Wea. Rev., 133, 3299-3314, 2005.

Xie, L., Pietrafesa, L. J., Bohm, E., Zhang, C., and Li, X.: Evidence and mechanism of hurricane Fran-induced ocean cooling in the Charleston trough, Geophys. Res. Lett., 25, 769-772, 1998.

Zedler, S. E., Dickey, T. D., Doney, S. C., Price, J. F., Yu, X., and Mellor, G. L.: Analyses and simulations of the upper ocean's response to Hurricane Felix at the Bermuda Testbed Mooring site: 13-23 August 1995, J. Geophys. Res., 107(C12), 3232 , doi:10.1029/2001JC000969, 2002.

Zedler, S. E., Niiler, P. P., Stammer, D., Terrill, E., and Morzel, J.: Oceans response to Hurricane Frances and its implications for drag coefficient parameterization at high wind speeds, J. Geophys. Res., 114, C04016, doi:10.1029/2008JC005205, 2009. 